\title{
Intraseasonal Variability of the Diurnal Cycle of Precipitation in the Philippines
}

\author{
Michael B. NATOLI AND ERIC D. MALONEY \\ Department of Atmospheric Science, Colorado State University, Fort Collins, Colorado
}

(Manuscript received 31 May 2019, in final form 29 August 2019)

\begin{abstract}
Precipitation in the region surrounding the South China Sea over land and coastal waters exhibits a strong diurnal cycle associated with a land-sea temperature contrast that drives a sea-breeze circulation. The boreal summer intraseasonal oscillation (BSISO) is an important modulator of diurnal precipitation patterns, an understanding of which is a primary goal of the field campaign Propagation of Intraseasonal Tropical Oscillations (PISTON). Using 21 years of CMORPH precipitation for Luzon Island in the northern Philippines, it is shown that the diurnal cycle amplitude is generally maximized over land roughly 1 week before the arrival of the broader oceanic convective envelope associated with the BSISO. A strong diurnal cycle in coastal waters is observed in the transition from the inactive to active phase, associated with offshore propagation of the diurnal cycle. The diurnal cycle amplitude is in phase with daily mean precipitation over Mindanao but is nearly out of phase over Luzon. The BSISO influence on the diurnal cycle on the eastern side of topography is nearly opposite to that on the western side. Using wind, moisture, and radiation products from the ERA5 reanalysis, it is proposed that the enhanced diurnal cycle west of the mountains during BSISO suppressed phases is related to increased insolation and weaker prevailing onshore winds that promote a stronger sea-breeze circulation when compared with the May-October mean state. Offshore propagation is suppressed until ambient midlevel moisture increases over the surrounding oceans during the transition to the active BSISO phase. In BSISO enhanced phases, strong low-level winds and increased cloudiness suppress the sea-breeze circulation.
\end{abstract}

\section{Introduction}

The tropical diurnal cycle has been of great interest to the scientific community for many decades. The "Maritime Continent" (MC) in particular presents an intriguing challenge, with its complex topography situated among some of the warmest sea surface temperatures (SST) on the planet (Saito et al. 2001; Qian 2008; Wang and Sobel 2017). The diurnal cycle is a critical component of the variability in MC precipitation (Bergemann et al. 2015), which provides a notable source of convective heating for the global atmospheric circulation (Ramage 1968; Yamanaka et al. 2018). However, a highresolution cloud-resolving model is often required to accurately capture the detailed features of the precipitation distribution (Sato et al. 2009; Birch et al. 2015), and errors in global climate models in this region cascade into substantial simulation errors from pole to pole (Neale and Slingo 2003; Inness and Slingo 2006).

Corresponding author: Michael B. Natoli, mbnatoli@atmos. colostate.edu
A greater understanding of the diurnal cycle and its variability is required in order to benefit forecast skill locally and convective parameterizations. This paper aims to add to the body of work on the variability of the diurnal cycle on intraseasonal time scales. Here, the focus is on the overlooked boreal summer season with a focus on the Philippines and South China Sea.

The mean state of the MC diurnal cycle has been studied extensively, primarily focusing on the islands of Sumatra, Borneo, and New Guinea. Houze et al. (1981) presented field observations that showed an extremely regular diurnal cycle over both land and ocean near Borneo. Across the MC region, differential daytime heating between land and water due to the difference in heat capacity leads to sea-breeze circulations that converge near the center of the islands, and combine with mountain-valley breezes to enhance convection over mountains (Qian 2008). Cells begin to merge and organize, particularly over larger islands, leading to a late afternoon peak in precipitation rates (Dai 2001; Yang and Slingo 2001; Mapes et al. 2003b; Mori et al. 2004; Kikuchi and Wang 2008; Wu et al. 2008, 2009; Tabata et al. 2011; 
Biasutti et al. 2012; Hassim et al. 2016). In the evening, evaporation of rainwater after convection is of primary importance for cooling the land surface, and radiative cooling is secondary (Wu et al. 2008, 2018). Coastal precipitation contributes more total precipitation to the tropical water budget than its proportion of tropical area would imply if precipitation were distributed evenly (Bergemann et al. 2015; Ogino et al. 2016).

Yang and Slingo (2001) found a striking tendency toward offshore propagation of the diurnal cycle across the global tropics. Their hypothesis originally proposed that this propagation was due to diurnally generated gravity waves radiating away from land. This idea has been supported by successive papers, showing very regular patterns of offshore propagation likely due to a gravity wave that destabilizes the atmosphere over coastal waters (Mapes et al. 2003a; Mori et al. 2004; Love et al. 2011; Hassim et al. 2016; Vincent and Lane 2016; Yokoi et al. 2017; Vincent and Lane 2018; Wu et al. 2018). Westward propagation is generally favored across the warm pool, but there is significant variability in the persistence and direction of diurnally propagating convective systems, likely related to fluctuations in the background wind profile (Mori et al. 2004; Sakurai et al. 2005; Ichikawa and Yasunari 2006, 2008; Keenan and Carbone 2008; Kikuchi and Wang 2008; Rauniyar and Walsh 2011; Tulich and Kiladis 2012; Wang and Sobel 2017; Yanase et al. 2017) and the availability of freetropospheric moisture in the offshore environment (Hassim et al. 2016; Vincent and Lane 2017, 2018).

Variability on intraseasonal time scales, broadly defined as 20-100 days, has been another major area of interest in tropical meteorology. The Madden-Julian oscillation (MJO) is the primary mode of variability on these time scales. First discovered by Madden and Julian (1971), the MJO consists of a broad, eastward-propagating region of enhanced convective activity associated with anomalous divergence in the upper troposphere and convergence near the surface (Madden and Julian 1972, 1994; Hendon and Liebmann 1994; Hendon and Salby 1994). MJO heating forces an equatorial Kelvin wave to the east with symmetric Rossby waves poleward and to the west (Gill 1980) as well as a Rossby-wave train that extends into the extratropics, primarily in the winter hemisphere (Knutson and Weickmann 1987; Matthews et al. 2004).

The interactions between the diurnal cycle and the MJO may be important to the dynamics of each. Sui and Lau (1992) showed that the diurnal cycle over the $\mathrm{MC}$ islands tends to be suppressed during the convectively active MJO phase. A peak in the amplitude of the diurnal cycle during the suppressed period or in the lead up to the active phase has been shown in many successive studies for Sumatra, Borneo, and New Guinea (Ichikawa and Yasunari 2006; Fujita et al. 2011; Rauniyar and Walsh 2011; Oh et al. 2012; Peatman et al. 2014; Birch et al. 2016; Vincent and Lane 2016; Sakaeda et al. 2017; Vincent and Lane 2017). Recent field data from Sumatra has shown a robust diurnal cycle in the suppressed and transition MJO phases, until the onset of low-level westerly winds in the active phase dramatically alters the diurnal cycle character (Wu et al. 2017; Yokoi et al. 2017; Wu et al. 2018). Katsumata et al. (2018) noted a strong, regular diurnal cycle that initiates over Java Island in Indonesia and propagates offshore during a convectively suppressed MJO period.

Peatman et al. (2014) took a more comprehensive look at this behavior, finding that the amplitude of the diurnal cycle peaks roughly one eighth of an MJO cycle before the main convective anomaly arrives, and that the diurnal cycle determines the daily mean precipitation rate over the MC islands considered. They proposed that this pattern was due to high insolation combined with frictional moisture convergence associated with the leading Kelvin wave and the Rossby wave trailing the suppressed anomaly, a contention supported by subsequent models and observations (Birch et al. 2016).

While the boreal wintertime MJO is maximized near the equator, it takes on a different character in the boreal summer season when it is sometimes referred to as the boreal summer intraseasonal oscillation (BSISO). In May-October, the convective anomaly propagates both northward and eastward into the Asian summer monsoon region (Lau and Chan 1986; Lawrence and Webster 2002; Lee et al. 2013; Jiang et al. 2018), modulating the onset of the monsoon and its active and break periods during the height of the season (Wang and Xu 1997; Annamalai and Slingo 2001; Annamalai and Sperber 2005). A convective heating anomaly centered off the equator then leads to an asymmetrical large-scale circulation response (Gill 1980; Hendon and Liebmann 1994; Kemball-Cook and Wang 2001). The BSISO mode has been examined less than its wintertime counterpart, and thus is the focus of this study.

There has been more limited work exploring interactions between the BSISO and the diurnal cycle over the Philippines and South China Sea. Chen and Takahashi (1995) used satellite derived brightness temperatures to indicate a weaker diurnal cycle over the South China Sea (SCS) during the suppressed intraseasonal oscillation (ISO) period, concurrent with an active diurnal cycle over surrounding landmasses, similar to what has been found for the wintertime MJO near the equator. More recent work using the Tropical Rainfall Measuring Mission (TRMM) Precipitation Radar has detected distinct behavior in the SCS diurnal cycle in each BSISO 
regime (Ho et al. 2008). In the SCS near the Philippines, a robust morning peak was found during the ISO active phase, which the authors connected to convergence between the land breeze and the prevailing monsoon flow. However, the same region experienced a late evening peak in the diurnal cycle during the ISO inactive period that was more directly tied to convection propagating offshore from the Philippines. Park et al. (2011) examined a case study in a model, reanalysis, and multisatellite rainfall estimates to connect this morning maximum during westerly wind burst (active ISO) periods with the large-scale diurnal cycle over the Asian continent. Recently, Xu and Rutledge (2018) showed that deep convective activity and lightning associated with an active diurnal cycle are maximized over the Philippines during the convectively suppressed phase, consistent with prior work over the other MC islands.

This paper will examine the relationship between the diurnal cycle and the boreal summer mode of the MJO with a focus on the Philippines. The goal is to determine the extent to which the early peak in the diurnal cycle amplitude noted by Peatman et al. (2014) is present in boreal summer over other parts of the MC farther from the equator. This study will also focus on the entire BSISO life cycle, with a particular focus on the transition regime, rather than comparing the active and suppressed periods in aggregate. Furthermore, the applicability of the mechanisms proposed by Peatman et al. (2014) will be assessed here for a new season and new region in order to build toward a consistent theory explaining the ISO-diurnal cycle scale interactions. The Climate Prediction Center (CPC) morphing technique (CMORPH) precipitation dataset (see section 2a), which provides improved spatial and temporal resolution, has not yet been used for this application. While exploring the feedback of the diurnal cycle to the ISO is not the focus of this paper, prior work has suggested that the specifics of the diurnal cycle could be an important factor determining if the ISO can successfully propagate through the MC (Hagos et al. 2016; Zhang and Ling 2017). Section 2 describes the datasets and methods that are employed in this study. The mean state diurnal cycle over the Philippines is reviewed in depth in section 3, followed by an analysis of its changes with BSISO phase in section 4. Section 5 explores some potential mechanisms proposed to explain the findings of section 4, with a summary and conclusions in section 6 .

\section{Data and methods}

\section{a. Datasets}

The primary precipitation dataset employed in this study is from CMORPH (Joyce et al. 2004; Xie et al. 2017).
Precipitation accumulation estimates are provided at 30-min temporal resolution and 8-km spatial resolution (at the equator), covering $60^{\circ} \mathrm{S}-60^{\circ} \mathrm{N}$. This technique uses microwave precipitation estimates from satellites in low-Earth orbit to identify specific precipitation features, and then tracks them through time and space using infrared retrievals from geostationary satellites. Successive microwave estimates are morphed through a weighted linear interpolation. As a result, infrared information is only used to track systems identified by microwave estimates rather than adding additional calibrated precipitation estimates. Estimates are then bias corrected using gauge data over land and the Global Precipitation Climatology Project over ocean (Xie et al. 2017). While such bias correction improves the accuracy of satellite precipitation estimates over complex terrain, there are still quantitative weaknesses in products such as CMORPH. For this study, CMORPH precipitation estimates are considered for boreal summers (May-October) from 1998 to 2018. Since the analysis period includes several strong El Niño events, the analysis of this paper was repeated by excluding the summers in which a strong El Niño event was decaying (1998, 2010, and 2016), and the conclusions were found to be unchanged.

The fifth major global reanalysis produced by the European Centre for Medium-Range Weather Forecasts (ERA5) [Dee et al. 2011; Copernicus Climate Change Service (C3S; C3S 2017)] is used for surface downwelling solar radiation, surface wind, and total column water vapor. In addition, reanalyses of specific humidity and wind are used at pressure levels every $50 \mathrm{hPa}$ from 1000 to $100 \mathrm{hPa}$. All variables are considered at 1 -h temporal resolution on a $0.125^{\circ}$ spatial grid from 1998 to 2018 to be consistent with the CMORPH period of record. While there are known weaknesses to reanalyses (i.e., Birch et al. 2015), the high resolution and coverage in the spatial and temporal dimensions make it an attractive and useful option.

Outgoing longwave radiation (OLR) is used as a proxy for the large-scale convection associated with the BSISO. In this study, the OLR estimates derived and interpolated from the Advanced Very High Resolution Radiometer (AVHRR) are used, available at $2.5^{\circ}$ spatial and daily temporal resolution (Liebmann and Smith 1996). Land surface topography data is also included to help interpret the findings in this study, provided at 2-min spatial resolution from the National Oceanic and Atmospheric Administration (NOAA) ETOPO2 dataset (National Geophysical Data Center 2006).

The BSISO index used in this study is that by Lee et al. (2013), which is based on the first two multivariate empirical orthogonal functions of OLR and 850-hPa zonal 
wind from May to October over the Asian summer monsoon region. No spatial or temporal filtering is used to calculate this index, which means that it does not exclusively capture canonical northward propagating BSISO events with an intraseasonal period (Wang et al. 2018). However, it is designed to capture structures that explain the most variance in the region of interest, making it an attractive option for examining the behavior of the diurnal cycle under varying large-scale regimes. The results of this study were replicated with other commonly used BSISO indices (Wheeler and Hendon 2004; Kikuchi et al. 2012; Kiladis et al. 2014), and the conclusions remain the same.

\section{b. Compositing}

Composite diurnal cycles are created for CMORPH precipitation by first converting 30-min accumulation to average precipitation rate in millimeters per hour, and then averaging all estimates taken at the same time of day for each point. The boreal summer composite diurnal cycle includes all days in May-October. A similar process was done for surface wind estimates from ERA5, but at 1-hourly temporal resolution. In addition, separate composite diurnal cycles were calculated for each individual BSISO phase as defined by the Lee et al. (2013) index. In this case, only days in boreal summer on which the index recorded an amplitude (defined as the square root of the sum of the squares of the first two principal components) of greater than or equal to 1.0 were included, resulting in eight composite diurnal cycles for each of the eight BSISO phases. The composites were created from 292, 370, 257, 245, 347, 264, 308, and 309 days, respectively.

The first diurnal harmonic is calculated from the composite diurnal cycle for several datasets in this study. The diurnal amplitude refers to the amplitude of the first diurnal harmonic of the composite diurnal cycle, either for the full boreal summer, or the individual BSISO phase. Diurnal range refers to the difference between the maximum and minimum of the composite diurnal cycle. Both of these methods are different ways of looking at the amplitude of the diurnal cycle and will be used when appropriate. The diurnal range tends to be significantly noisier, and might not necessarily reflect a smooth diurnal sine curve. However, the diurnal amplitude does not accurately represent days with a short, narrow peak in precipitation rate. Anomalies of these measures of the diurnal cycle are also included, defined as the difference between, for example, the diurnal amplitude of the BSISO composite diurnal cycle in a given phase and the full boreal summer composite diurnal amplitude.

\section{c. Statistical significance}

Statistical significance is included for the differences in precipitation statistics between the full boreal summer composite and each BSISO phase with the null hypothesis that any differences are due to random chance. In this study, a statement of statistical significance means that this hypothesis can be rejected at the $95 \%$ confidence level. A bootstrap was used to create 1000 random composite diurnal cycles each made from 79 simulated events. This number was chosen as it was the smallest number of independent BSISO events during the period 1998-2017 (in May-October only) for any of the eight phases, where an independent BSISO event was defined as a period of consecutive days with the index in the same phase and an amplitude greater than 1.0.

Since the compositing method used may sample multiple days from the same BSISO event, the bootstrap must also sample consecutive days. The length of observed BSISO events varies widely from one to fifteen days. To replicate this as closely as possible in the random composites, a Poisson distribution was employed to simulate the event length. The probability of an event of length $k+1$ days occurring is given by

$$
P(\text { event is } k+1 \text { days long })=e^{-\lambda} \frac{\lambda}{k !},
$$

where the rate parameter $\lambda$ was equal to 1.92 days, the average number of additional days beyond the first in all real BSISO events. All days were added to the random composite with equal weighting, giving each of the 1000 composites an average of 230 total days from 79 independent events. The smallest number of total days included in any one phase composite was 256 days, and thus this method provides a fairly conservative comparison.

\section{Mean diurnal cycle}

In this section, the mean state of the diurnal cycle in boreal summer (May-October) over the Philippine archipelago is examined. Figure 1 shows the topography of the Philippines. The two major islands, Luzon and Mindanao, (the northernmost and southernmost large island, respectively) are characterized by mountains in excess of $2000 \mathrm{~m}$ above sea level. The complex topography of the MC collocated with warm seas and a moist tropical atmosphere makes this region of prime interest for studies of the diurnal cycle (Qian 2008).

Figure 2 shows some important features of the diurnal cycle over the Philippines and surroundings waters. Figure 2a shows the diurnal amplitude of CMORPH precipitation in boreal summer, computed by fitting a sine curve to the May-October composite diurnal cycle 


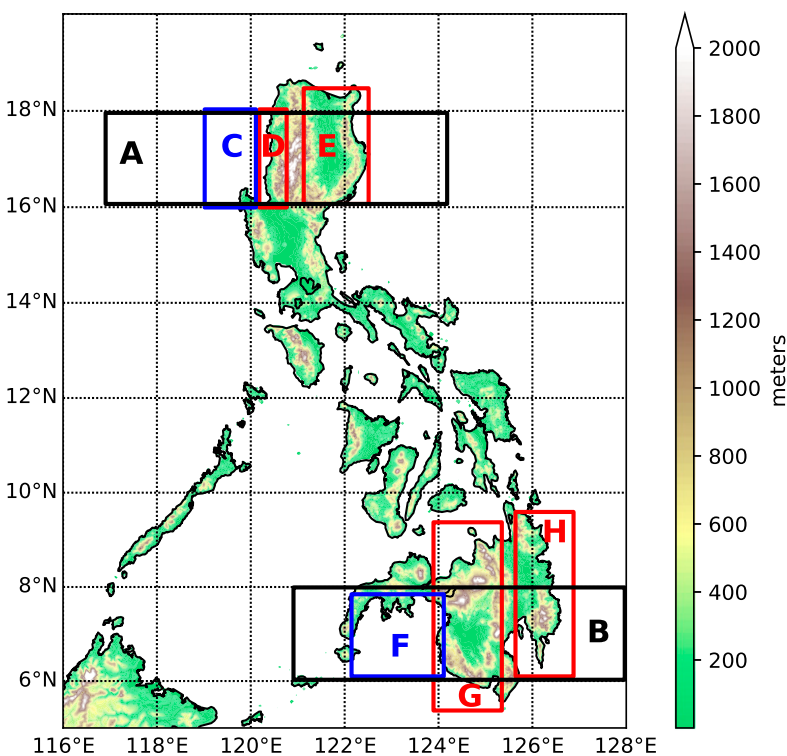

FIG. 1. NOAA ETOPO2 topography (m) over the Philippines, showing the boxes of spatial averaging that are used later.

at each point. A preference for high-amplitude diurnal cycles over land is evident, particularly over the larger islands of Luzon and Mindanao, consistent with many prior studies (Chen and Takahashi 1995; Biasutti et al. 2012; Kikuchi and Wang 2008; Ohsawa et al. 2001; Qian 2008; Saito et al. 2001). Figure 2c shows how well the composite diurnal cycle is described by the sine curve with a period of one day. The variance explained by the first harmonic is generally quite high over land and surrounding waters, with some low values in coastal waters near the smaller islands of the Philippines, possibly due to interfering propagation patterns.

Consistent propagation of diurnal convection is apparent in the peak hour of the first diurnal harmonic displayed in Fig. 2b. Over the smaller islands of the central Philippines, precipitation rates tend to peak in the late afternoon hours, around 1630 local solar time (LST). However, the peak is noticeably later over large islands, at around 1800 LST (Qian 2008; Saito et al. 2001; Yang and Smith 2006). This is supported by prior studies that have explored the connection between island size and the diurnal cycle more directly (Robinson et al. 2011; Sobel et al. 2011; Cronin et al. 2015; Kawecki and van den Heever 2019). In the South China Sea to the west of the Philippine Islands, evidence for offshore propagation exists, as peak hours get progressively later away from shore. Offshore propagation, with westward propagation favored, has been shown to be relatively ubiquitous across the islands of the MC (Ichikawa and Yasunari 2006; Love et al. 2011; Mori et al. 2004; Tulich and Kiladis 2012; Yang and Slingo 2001).
The offshore propagation is shown more convincingly in Fig. 3, which displays a time-longitude cross section of precipitation rates averaged over latitudes characteristic of the northern part of Luzon island (box A in Fig. 1). Precipitation rates begin to increase over peak topography on the western side of the island around midday before spreading both east and west. Peak rainfall occurs around 1800 local Philippine time (LT), followed by a gradual decay as the precipitation maximum propagates westward as far as $200-\mathrm{km}$ offshore into the early morning hours at roughly $6.3 \mathrm{~m} \mathrm{~s}^{-1}$. Average precipitation rates drop to near zero during the early morning hours over land, while simultaneously peaking offshore. Eastward propagation is less apparent than that toward the west, although there is evidence of an overnight increase in offshore precipitation in the Philippine Sea, likely associated with the land-sea breeze (Houze et al. 1981).

This analysis has also been done for other satellitederived precipitation products. The TRMM 3B42 product synthesizes precipitation estimates from multiple satellite retrievals in the microwave band, and fills in the gaps with measurements in the infrared band (Huffman et al. 2007). The high-quality version (3B42HQ) only uses the calibrated microwave retrievals. Both versions show a similar pattern to CMORPH (not shown). The TRMM Precipitation Radar (Iguchi et al. 2000) also supports these results, but tends to show a slightly earlier peak in the diurnal cycle when compared to TRMM and CMORPH, behavior also seen in previous work (e.g., Yamamoto et al. 2008). The rest of this paper will examine how diurnal cycle behavior changes with the BSISO along with the variations in environmental conditions that drive such changes.

\section{BSISO modulation of the diurnal cycle}

\section{a. General impact}

This section will explore changes in the diurnal cycle associated with the BSISO after first reviewing the general influence of the BSISO on the region of interest. The large-scale structure of the BSISO anomalies in OLR and 850-hPa winds is shown in Fig. 4, constructed by averaging the anomalies relative to the seasonal cycle on all days in a given phase. The seasonal cycle was defined by a daily climatology smoothed by an 11-day centered running mean. The BSISO daily mean precipitation anomalies near the Philippines are isolated in Fig. 5. Phases 1-3 generally see statistically significant decreases in average precipitation rate on both sides of the Philippine Islands, collocated with large-scale positive OLR anomalies and easterly wind anomalies 

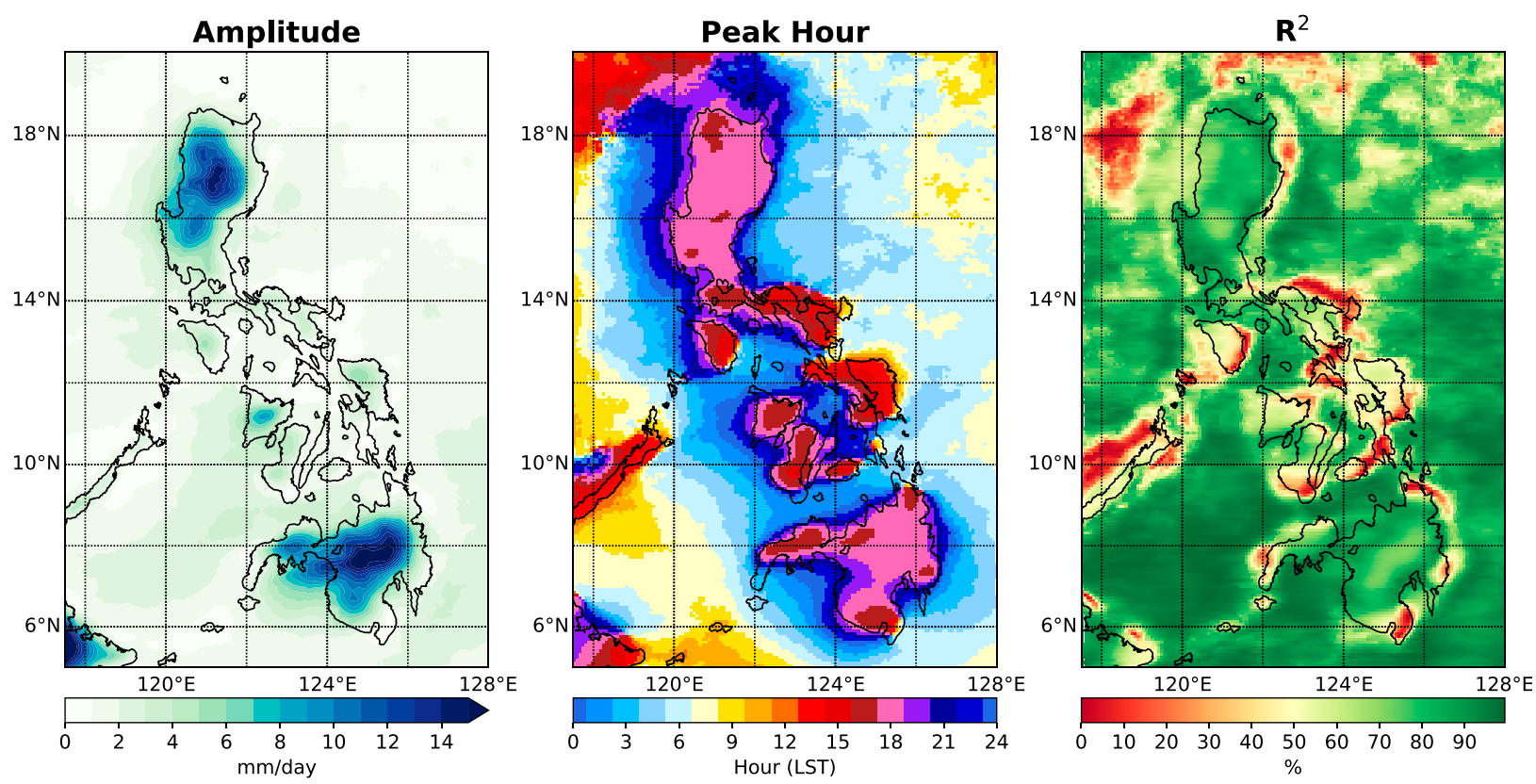

FIG. 2. From CMORPH precipitation, (a) the amplitude of the first diurnal harmonic of the boreal summer composite diurnal cycle, (b) its peak hour (LST), and (c) the variance in the boreal summer composite diurnal cycle explained by the first diurnal harmonic.

(Fig. 4). These phases will be referred to as the BSISO suppressed or inactive period. Phases 5-7 represent the BSISO enhanced or active period for the region, simultaneously presenting anomalously positive precipitation, negative OLR, and westerly wind. Daily mean precipitation anomalies over land are generally weaker than over nearby oceans, or even opposite in sign as over Mindanao. This behavior is consistent with that observed by $\mathrm{Xu}$ and Rutledge (2018) for this region, and also over other parts of the MC (Oh et al. 2012; Peatman et al. 2014; Sakaeda et al. 2017; Vincent et al. 2016).

Figure 6 shows anomalies in the amplitude of the first harmonic of the composite diurnal cycle as a function of BSISO phase. Strong anomalies are present over land and the coastal waters of the South China Sea. Statistically significant increases in diurnal amplitude are found in phases 3-4 over the western side of the Philippines and up to nearly $200-\mathrm{km}$ offshore. Positive anomalies are also present on the eastern side of the Philippines, but these are smaller in spatial extent. The opposite emerges toward the end of the active BSISO period (phases 7-8), when the diurnal cycle amplitude is smaller than average for western Luzon and Mindanao and the waters of the South China Sea immediately offshore. Many prior studies (e.g., Peatman et al. 2014; Sakaeda et al. 2017; Sui and Lau 1992; Vincent and Lane 2016; Xu and Rutledge 2018) have similarly shown a preference for strong diurnal cycles over land prior to the onset of enhanced ISO convection or during the suppressed period. However, this modulation of the diurnal cycle by the BSISO is not the universal on the subisland scale. For example, Fig. 6 shows that while the diurnal cycle is enhanced on the west side of the Philippines in phases 3-4, the opposite signal appears for a small section of land east of the high topography. The remainder of this section will highlight such behavior over the large islands of Luzon and Mindanao, and discuss the noteworthy modulation of offshore propagation of the diurnal cycle.

\section{b. Luzon}

Figure 7 a shows the latitudinally averaged composite diurnal cycles over Luzon as in Fig. 3 but for each phase of the BSISO. The differences from the boreal summer composite with statistical significance are shown in Fig. 7b. A diurnal cycle over land peaking in the late afternoon to early evening hours is present in every phase of the BSISO, consistent with $\mathrm{Xu}$ and Rutledge (2018). The afternoon maximum is enhanced during the suppressed BSISO phases (Fig. 4), while the morning minimum is reduced, thus amplifying the diurnal cycle. During the enhanced BSISO phases, precipitation rates are elevated at most hours of the day, except during the typical afternoon maximum.

The most interesting contrast between different BSISO phases from this figure is the modulation of westward offshore propagation of the diurnal cycle into the South China Sea. In phases 1-2, the early suppressed period, a strong diurnal cycle is present over land, but the precipitation maximum weakens rapidly overnight 


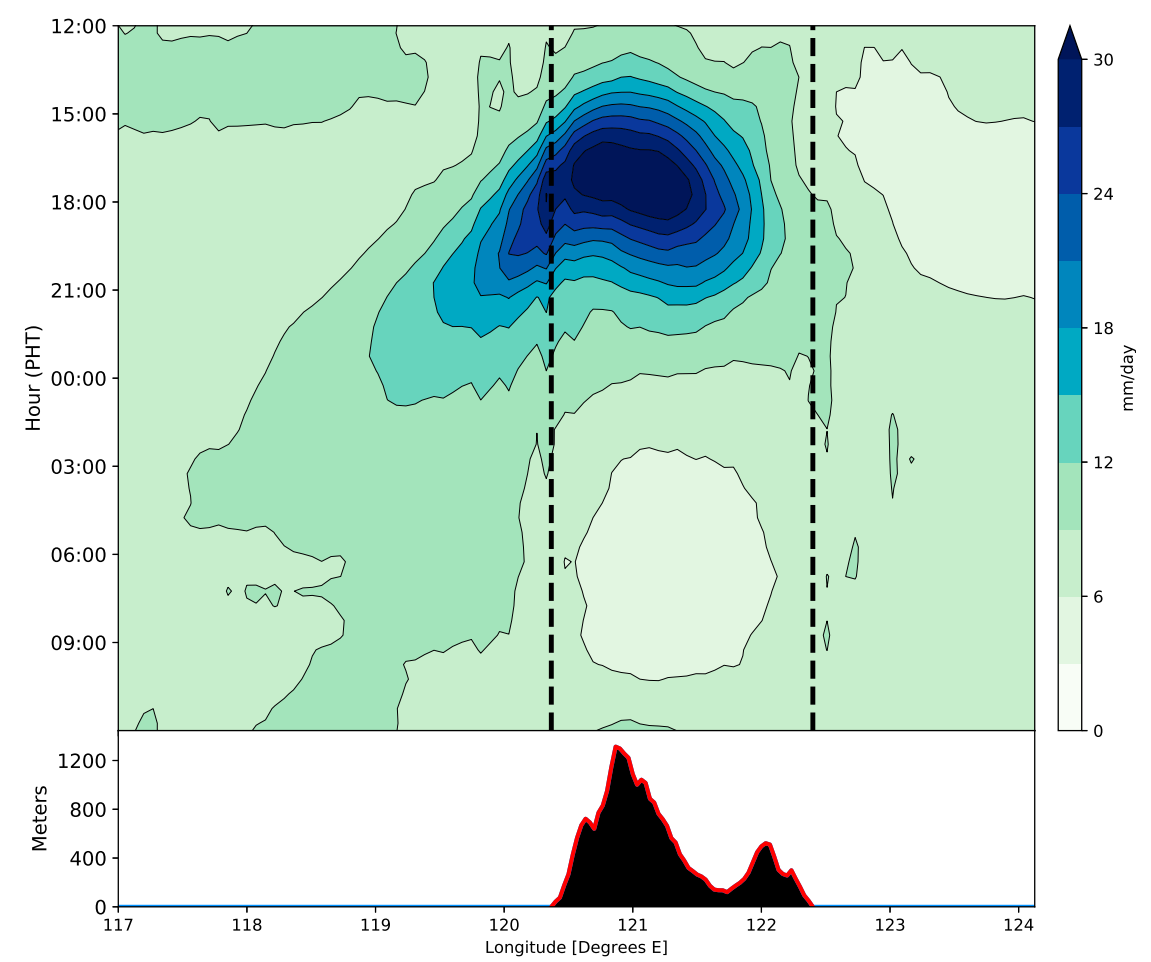

FIG. 3. Composite diurnal cycle based on CMORPH precipitation in boreal summer averaged latitudinally over box A (shown in Fig. 1), with average topography from NOAA ETOPO2 in the same cross section shown below the plot. The average longitudes of the shoreline are denoted as dotted black vertical lines.

and does not propagate far from the coast. In the late suppressed period and transition to active (phases 3-5), precipitation is still anomalously high during the afternoon maximum over land, but enhanced precipitation anomalies now extend far offshore overnight associated with westward propagation, consistent with studies focusing on other MC islands (Hassim et al. 2016; Vincent and Lane 2016; Yokoi et al. 2017; Wu et al. 2018). In phase 5 in particular, statistically significant enhancement of precipitation rates is found over $200-\mathrm{km}$ offshore during nighttime and early morning associated with the propagating diurnal cycle. Considering these results in the context of work showing that ISO propagation through the MC is associated with higher precipitation over the sea relative to land (Zhang and Ling 2017) leads to the speculation that offshore propagation of diurnal convection in advance of the onset of the main BSISO convective envelope could aid northward propagation into the SCS.

The opposite occurs in the late-active BSISO phases (6-8). Over land, precipitation rates are anomalously high at all times of day except during the usual afternoon maximum. In addition, the presence of a diurnal cycle is unclear over the SCS, consistent with a suppressed diurnal cycle over land with limited offshore propagation.
Any propagating signal is further muddled by the presence of elevated precipitation rates over the seas at all times of day associated with the active BSISO envelope. Similar behavior has been observed near Sumatra associated with the Years of the Maritime Continent field campaign (Wu et al. 2017, 2018; Yokoi et al. 2017).

Figure 8 shows spatial averages over select boxes chosen to highlight differences between ocean and land, and between land points east and west of high mountains. The top row (Figs. 8a,d) is constructed from a spatial average over ocean only to the west of Luzon (box C in Fig. 1), while the middle (Figs. 8b,e) and bottom rows (Figs. 8c,f) are averaged over land for western (box D) and eastern (box E) Luzon, respectively. Spatially averaged fields are shown as this tends to improve the performance of satellite-derived precipitation estimates (Tan et al. 2017). The left column shows composite diurnal cycles of precipitation for the May-October mean, each BSISO phase, and the $95 \%$ confidence bounds for randomly sampled diurnal cycles described in the section 2 . Anomalies of OLR, daily mean precipitation rate, and diurnal range are included in the right column with the $95 \%$ confidence bounds for the precipitation variables. The diurnal range is used here in place of the diurnal 

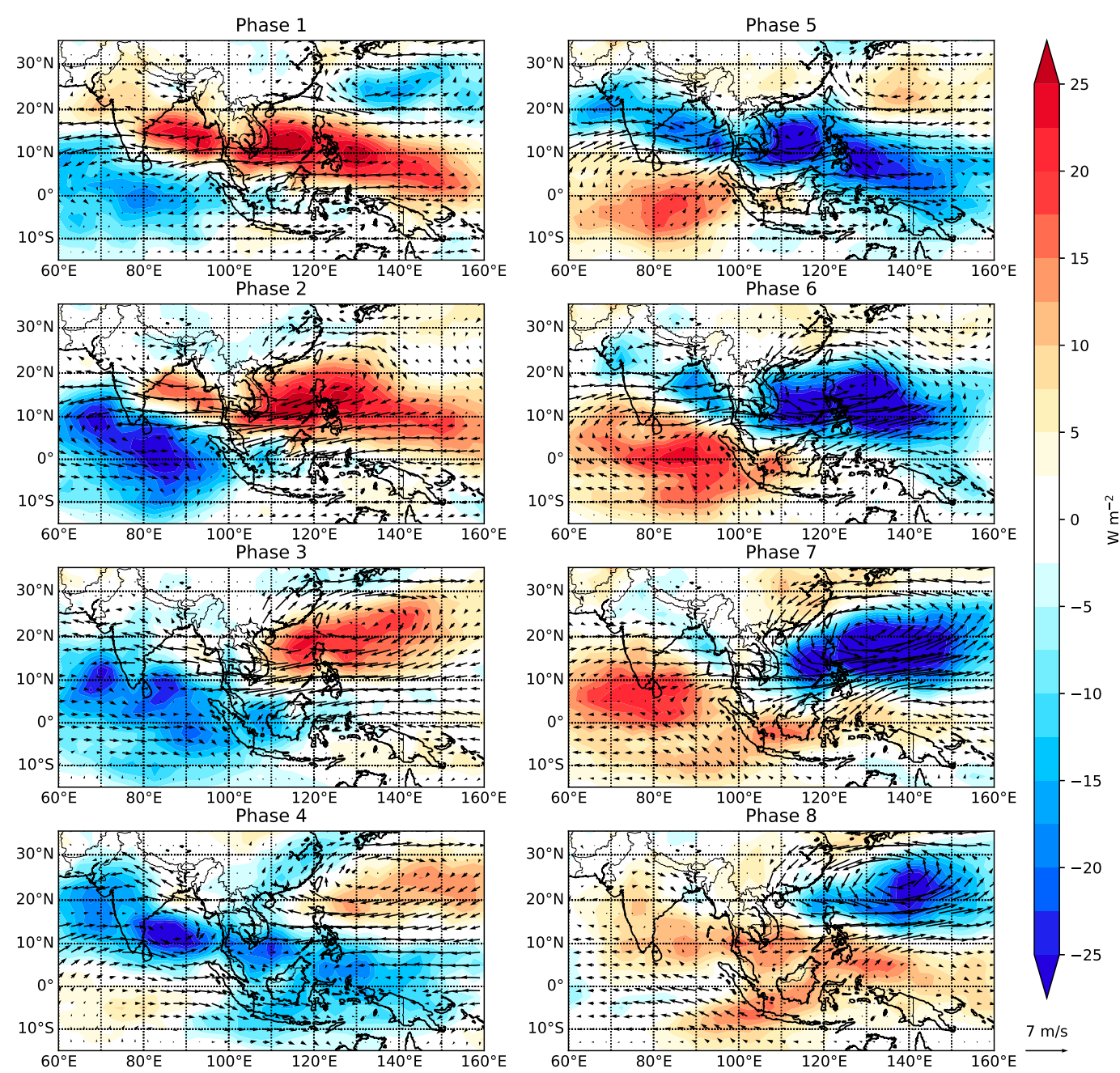

FIG. 4. Composite anomalies of AVHRR OLR (shading) and 850-hPa wind vector anomalies (arrows) from ERA5 by BSISO phase.

amplitude as Figs. 8a-c show that the diurnal range would indeed represent the difference between a narrow afternoon maximum and long morning minimum. After spatial averaging, the smoothing provided through use of the diurnal amplitude is not necessary. However, using the diurnal amplitude leads to the same conclusions (not shown).

Over western Luzon (Figs. 8b,e) the presence of a strong diurnal cycle in all BSISO phases is evident again. A statistically significant enhancement of the diurnal range occurs in phases 3-5 while the daily mean anomaly ranges from strongly negative in phase 3 to slightly positive in phase 5 (Fig. 8e). The opposite is seen in phases $7-8$, when the diurnal range is strongly reduced despite elevated daily mean precipitation rates. At least for land regions of western Luzon, BSISO modulation of overnight precipitation rates more than compensates for the changes to the daily maximum precipitation rate, resulting in the diurnal range and daily mean precipitation rates being out of phase.

The behavior present over western Luzon extends offshore into the South China Sea (Figs. 8a,b). The diurnal cycle is weaker here and peaks around three hours later on average than the land box over western Luzon, indicative of the arrival of convective systems propagating westward. In phases $1-2$, precipitation is suppressed at all times of day. Precipitation during the transition period (phases 3-4) is still suppressed during off peak hours, but it is near average during the typical late evening peak. Thus, a statistically significant enhancement of the diurnal amplitude is seen in phase 4-5 in Fig. $8 \mathrm{~d}$ while daily mean precipitation anomalies are near zero. The opposite behavior occurs as the BSISO transitions from active to suppressed conditions, in phases 7,8 , and 1 . There is some indication of the diurnal cycle taking on a more pure oceanic character, 
Daily Mean Anomaly
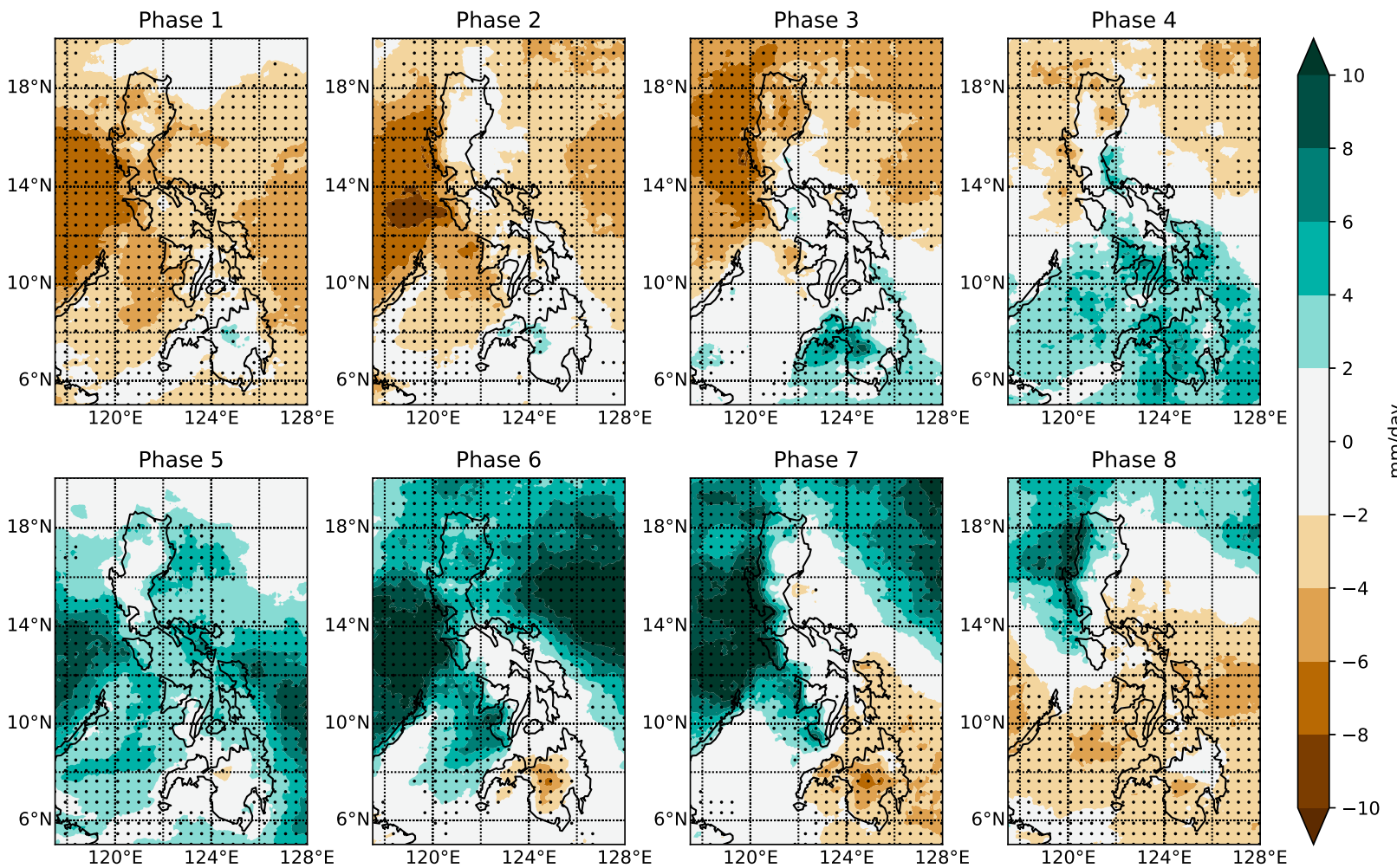

FIG. 5. Anomalies in daily mean CMORPH precipitation rate by BSISO phase, with statistical significance at the $95 \%$ level shown as dots.

peaking in the morning hours (Gray and Jacobson 1977; Park et al. 2011).

Interesting contrasts occur over eastern Luzon. East of the island's high topography (Figs. 8c,f), the BSISO modulation of the diurnal range is almost opposite to the western side of the island. In phases 3-4, the diurnal cycle amplitude is maximized on the western side (Fig. 8e) while the eastern side sees a statistically significant suppression of the diurnal cycle. The largest diurnal cycles over eastern Luzon are found in phase 8 . The daily mean precipitation rate and diurnal range are also much closer to being in phase. There appears to be strong BSISO modulation of the afternoon peak, but weaker modulation of the overnight minimum when compared to the western side, allowing the diurnal cycle amplitude to determine the daily mean precipitation rates. The results from this section suggest more nuance to the BSISO modulation of the diurnal cycle over the Philippines than previously discussed in the literature.

\section{c. Mindanao}

Similar behavior is evident over the southernmost major island of the Philippines. Figure 9 shows the diurnal cycles composited by BSISO phase averaged latitudinally over the island of Mindanao and adjacent ocean (box B in Fig. 1). It is important to note that due to its more southern location, Mindanao tends to be one BSISO phase ahead of Luzon. In other words, phases 8, 1 , and 2 are the main suppressed BSISO phases for this island, while the enhanced convective envelope passes through during phases 4-6 (Fig. 4). In phase 1, a strong diurnal cycle is present over the high topography of the central island, but precipitation rates decay rapidly overnight (Fig. 9a). However, during the transition to active (phases 2-4), anomalously high precipitation rates emerge over the island in the midafternoon, and then maintain strength as they propagate westward into the Moro Gulf into the overnight hours (Figs. 9a,b). This is most pronounced in phase 3 , which serves as the primary transition phase over Mindanao. In the later active phases of 5 and 6 , the afternoon maximum over land is drastically reduced, and westward propagation is not apparent.

Figure 10, similar to Fig. 8 but for Mindanao, supports these conclusions. Over central Mindanao (Fig. 10b), much of the variability in precipitation rate as a function of BSISO phase is found near the climatological peak time of the diurnal cycle (1500-2100 LT). The BSISO modulation of the diurnal cycle is much stronger here than it is for Luzon. In phases 3-4, as the 


\section{Diurnal Cycle Amplitude Anomaly}
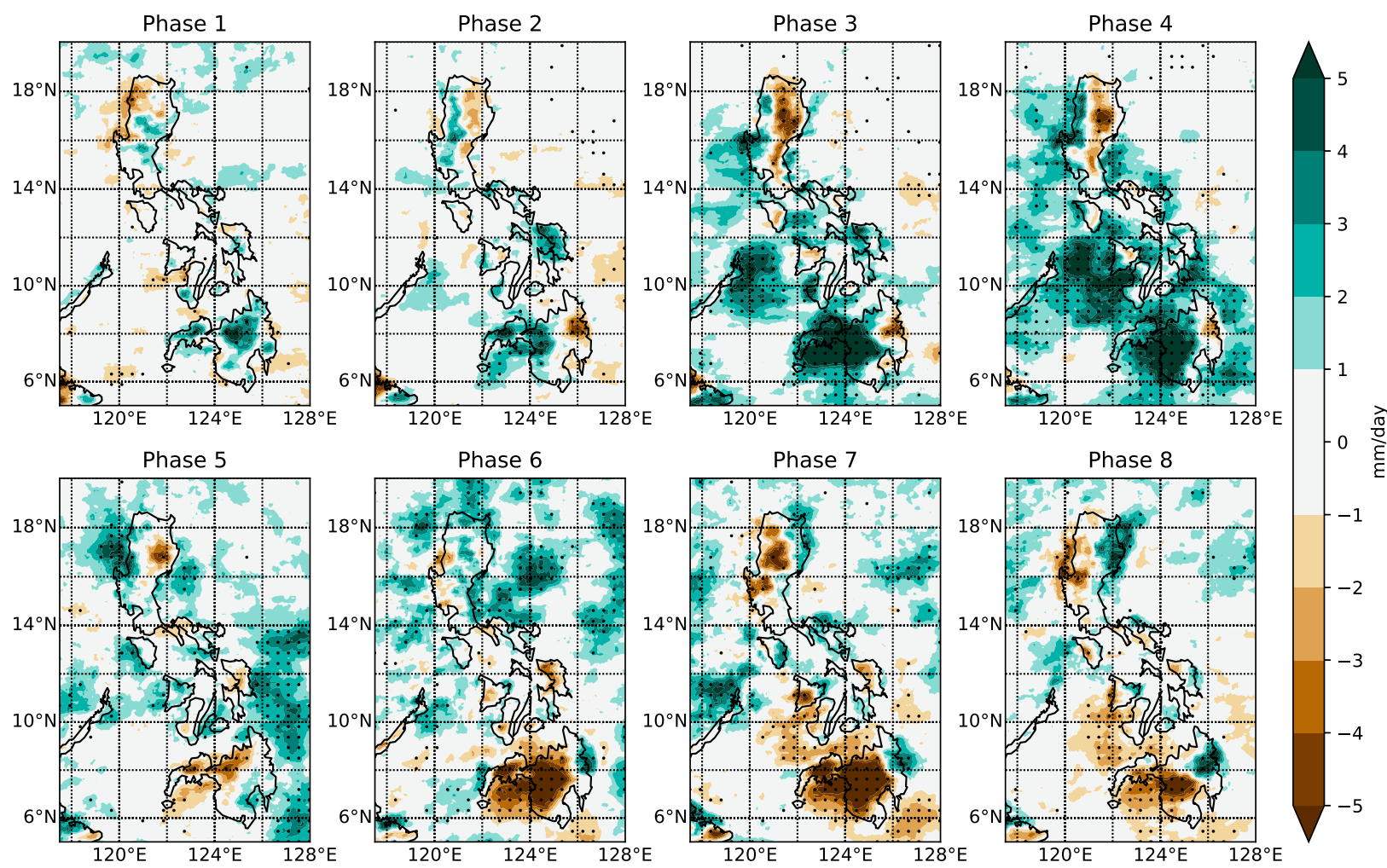

FIG. 6. BSISO composite anomalies in the amplitude of the first diurnal harmonic of CMORPH precipitation, relative to the full boreal summer composite diurnal cycle. Statistical significance at the $95 \%$ level is shown as dots.

BSISO transitions to its active phase, precipitation rates over central Mindanao (Fig. 10b) are strongly enhanced, well outside of the $95 \%$ confidence interval during the afternoon peak. Conversely, precipitation rates are strongly suppressed in the afternoon during the remainder of the convectively active BSISO phases and its transition back to suppressed. Both the diurnal range and daily mean precipitation rate have statistically significant positive anomalies during this period (Fig. 10e).

The diurnal cycle over the Moro Gulf (Fig. 10a) generally behaves similarly to that over the South China Sea near Luzon (Fig. 8a). CMORPH precipitation rates are strongly enhanced during the late evening peak of the diurnal cycle in phases $2-4$. A minimal diurnal cycle is present in the late active phases and transition to suppressed (phases 6-8). The same conclusion, that the strong, propagating diurnal cycle over coastal waters peaks prior to the peak of large-scale BSISO convection can be drawn from these results. The main difference between the two large islands is that the amplitude of the diurnal cycle generally determines the daily mean precipitation rate over Mindanao (Figs. 10d,e), but not Luzon (Figs. 8d,e). This close relationship between the diurnal amplitude and daily mean precipitation rate over Mindanao has been observed by studies focusing on other large MC islands (e.g., Peatman et al. 2014), but Luzon appears to behave differently.

The behavior over eastern Mindanao (Figs. 10c,f) is also dramatically different compared to the western side, similar to Luzon (Figs. 8c,f). In fact, eastern Mindanao (box $\mathrm{H}$ in Fig. 1) observes its strongest diurnal cycle in phase 8 , when the diurnal cycle over the central portion of the island is still strongly suppressed. In phases 2-4, when the portion of Mindanao west of the main topographic boundaries is recording a highamplitude diurnal cycle, the eastern side of the island sees a weaker than average diurnal cycle (although not statistically significant). These results suggest that the pattern of BSISO impact on the diurnal cycle is similar for the large islands of the Philippines. Intraseasonal variability has vastly different impacts depending on which side of the island's topography is being considered. In the next section, some potential mechanisms that could explain the patterns discussed here are presented, along with an explanation for this disparity between western and eastern portions of the islands. 


\section{(a) BSISO Composite}
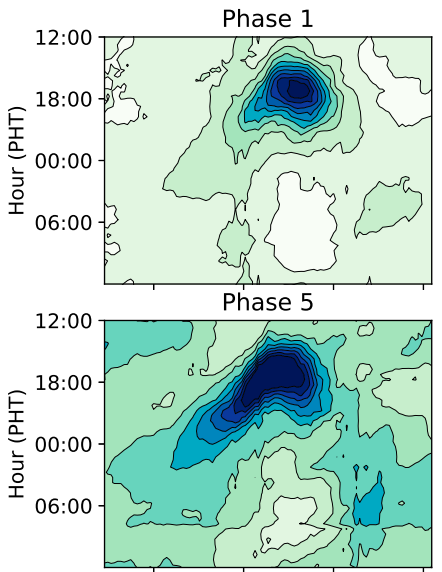

Phase 2

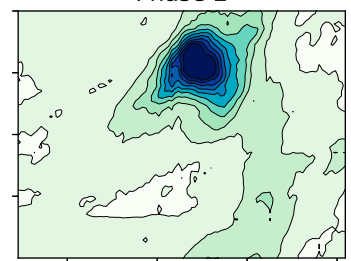

Phase 6

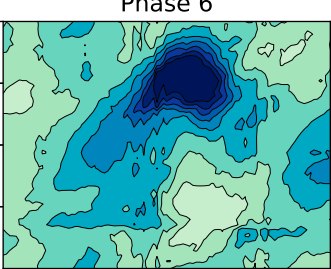

Phase 3

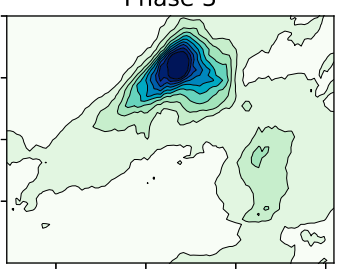

Phase 7

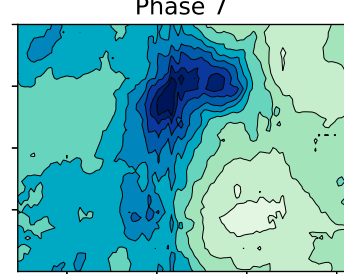

Phase 4

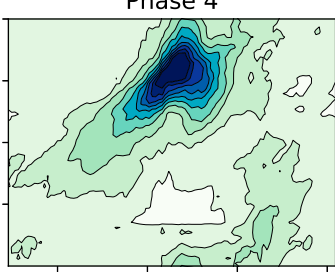

Phase 8

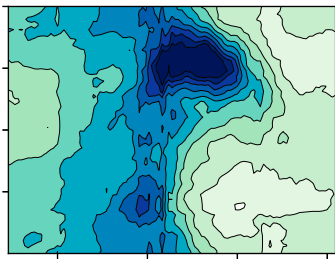

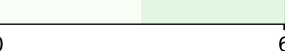

(b) Anomaly

$\mathrm{mm} /$ day

18

24

30

Phase 1
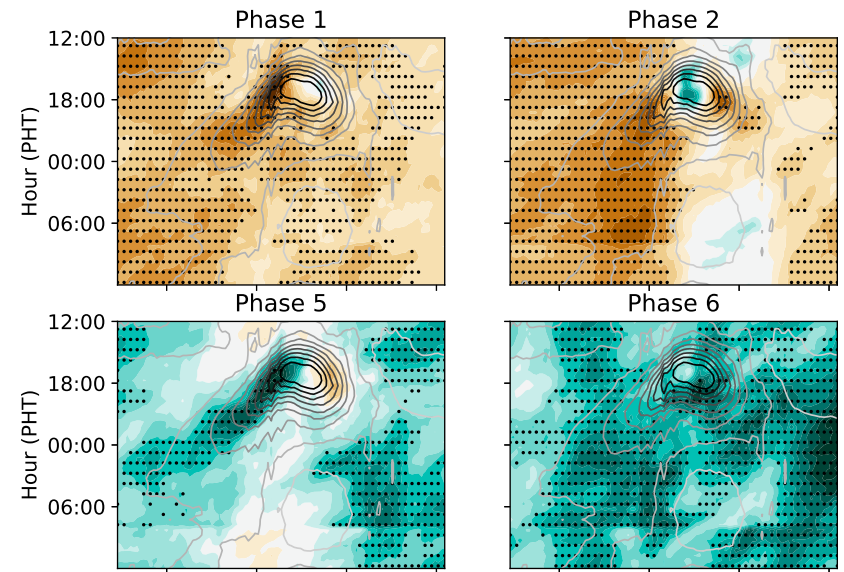

Phase 6
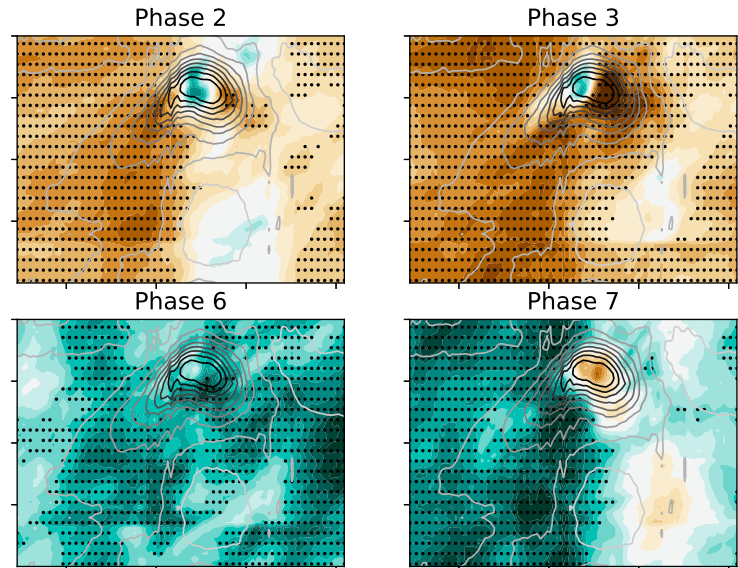

Phase 7
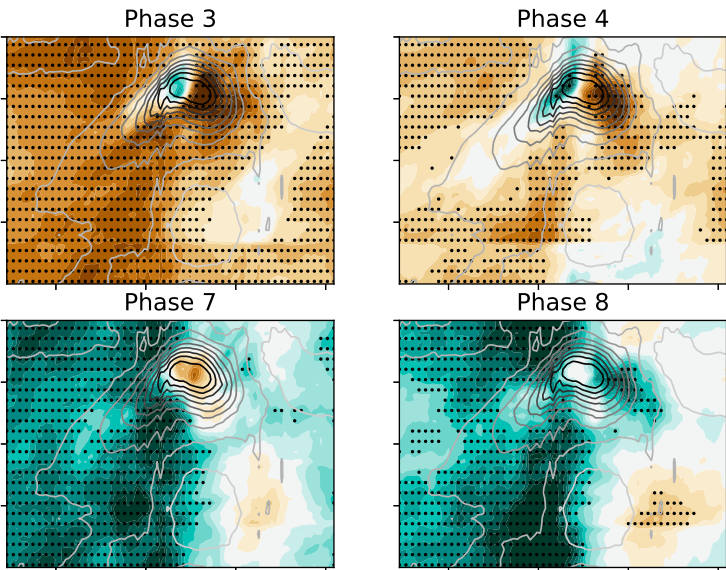

Phase 8
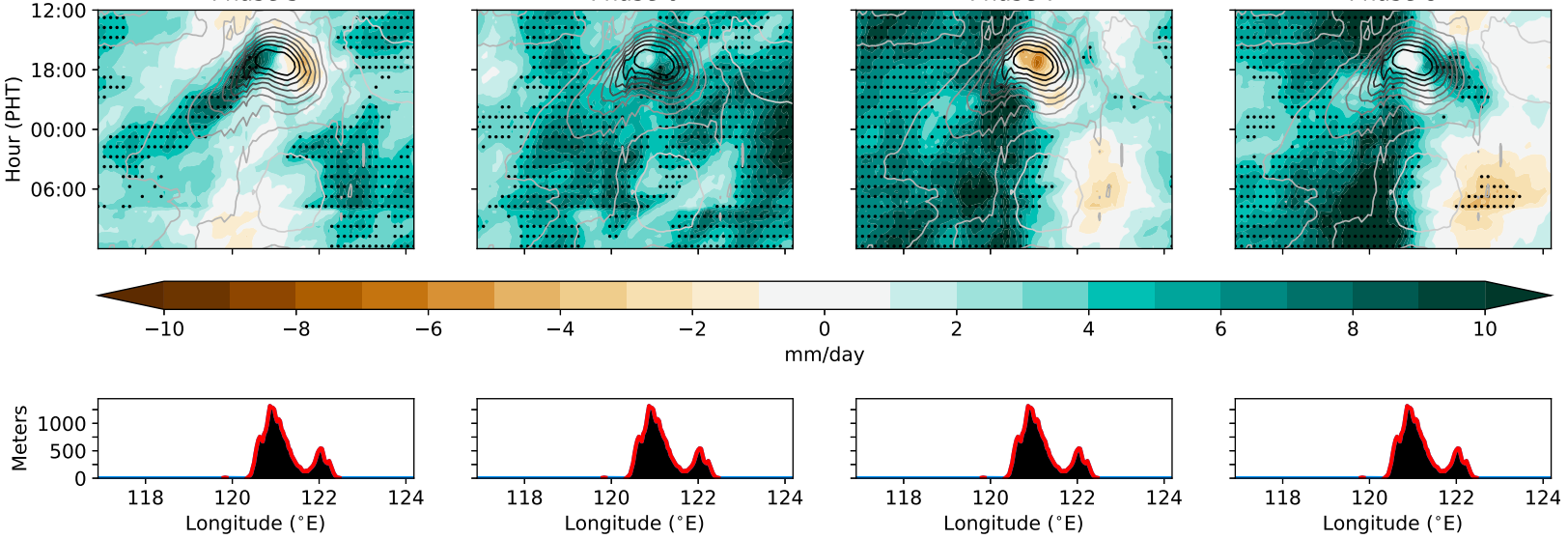

FIG. 7. (a) Composite diurnal cycle based on CMORPH precipitation by BSISO phase averaged latitudinally over box A (shown in Fig. 1) as in Fig. 3, and (b) the difference (shading) between these BSISO composite diurnal cycles and the full boreal summer composite diurnal cycle (shown in Fig. 3 and again in black and white contours here), with statistical significance superimposed as dots; the average topography from NOAA ETOPO2 is in the same cross section below each column.

While not shown in this paper, these results were also replicated with several other commonly used indices for the BSISO, namely the OLR MJO index (OMI; Kiladis et al. 2014), the real-time multivariate MJO index (RMM; Wheeler and Hendon 2004), and a bimodal ISO index described by Kikuchi et al. (2012). With varying clarity, this pattern of a peak in the amplitude of the diurnal cycle over the
Philippines and most extensive offshore propagation to the west prior to the arrival of BSISO convection was seen in all indices considered. Since the Lee et al. (2013) index describes the most variance in the South China Sea region (not shown), it tends to have the clearest response in the diurnal cycle, and thus it is shown in this paper. Furthermore, results from CMORPH are supported by TRMM 
(a) Coastal South China Sea

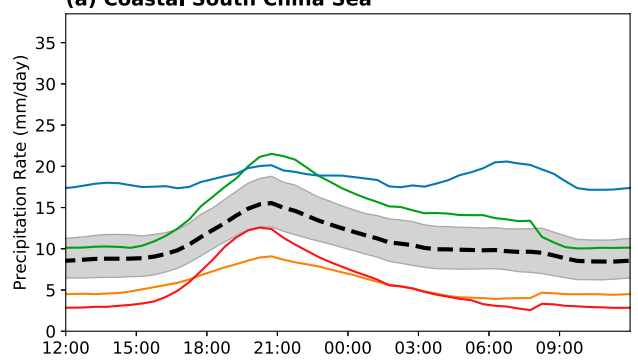

(b) Northwest Luzon

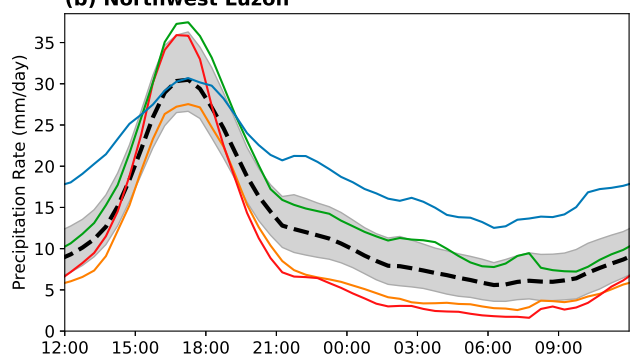

(c) Northeast Luzon

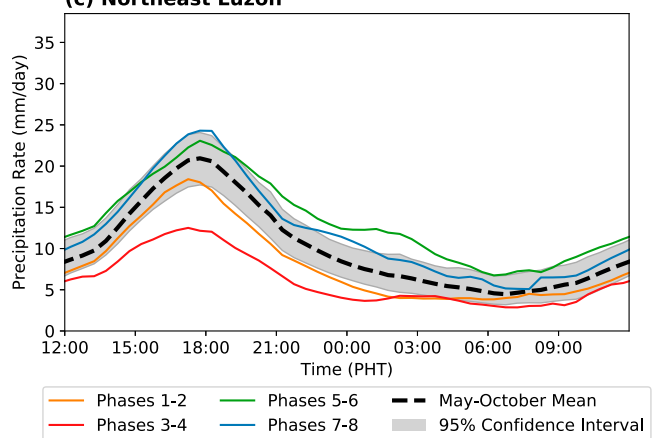

(d) Coastal South China Sea

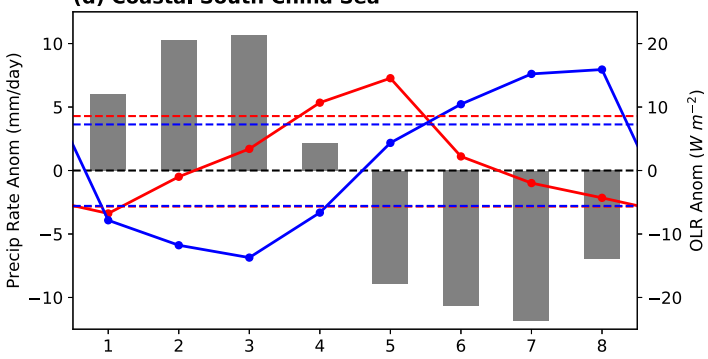

(e) Northwest Luzon

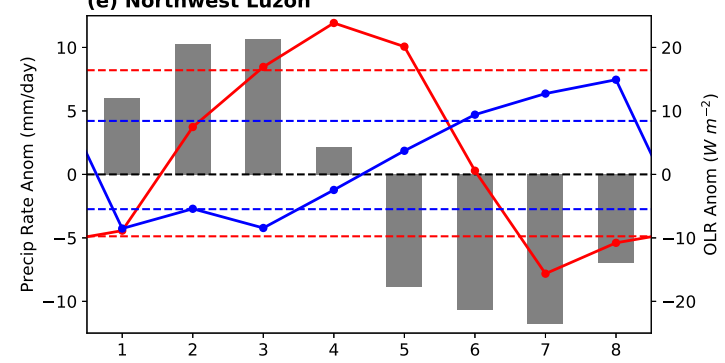

(f) Northeast Luzon

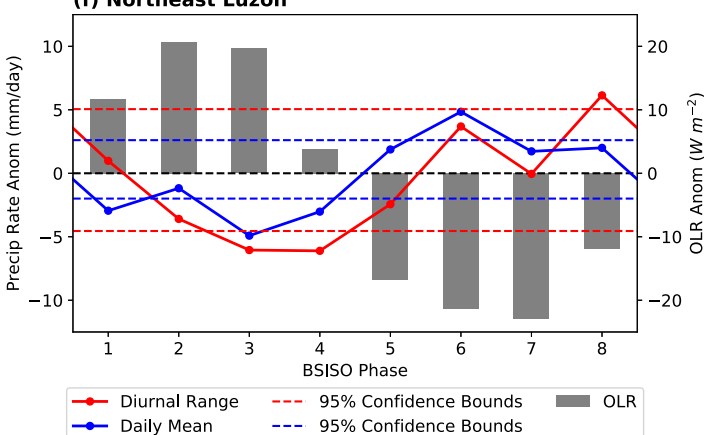

FIG. 8. The boreal summer composite diurnal cycle of CMORPH precipitation rate (black dotted lines) with $95 \%$ confidence bounds (gray shading), and composite diurnal cycles by BSISO phase (solid colored lines) (a) averaged over ocean points only inside box C (shown in Fig. 1) and averaged over land points only (b) inside box D and (c) in box E. (d)-(f) The corresponding difference between BSISO composite and May-October composite of OLR (gray bars), daily mean precipitation rate (solid blue lines), and diurnal range (solid red lines), with $95 \%$ confidence bounds for daily mean precipitation rate (blue dotted lines) and diurnal range of precipitation rate (red dotted lines), from the composite diurnal cycles shown in (a)-(c).

3B42 and TRMM 3B42HQ, indicating that these results are not a product of the precipitation dataset considered.

\section{Discussion}

In this section, potential mechanisms to explain the features observed in the last section will be discussed. Particularly, this section aims to explain 1) the enhanced diurnal cycle over land prior to the arrival of the main BSISO convective envelope, 2) the increased offshore propagation of diurnally generated convection during the transition to the active phase, and 3) the contrast with the behavior observed east of high topography, where the diurnal cycle amplitude appears to maximize at the end of the convectively active BSISO period.

\section{a. Insolation and the sea breeze}

Figure 11a shows surface insolation anomalies by BSISO phase. The BSISO convective envelope (Fig. 4) is associated with diminished surface insolation (Fig. 11a) via increasing cloudiness, in accordance with many previous studies (Johnson et al. 1999; Myers and Waliser 2003; Riley et al. 2011; Sakaeda et al. 2017). The Philippines receive more solar radiation during the suppressed phases, which supports an enhanced diurnal cycle over land. This is expected, since strong insolation will lead to greater contrast between land and sea due to a difference in thermal inertia, resulting in a strong sea-breeze 


\section{(a) BSISO Composite}
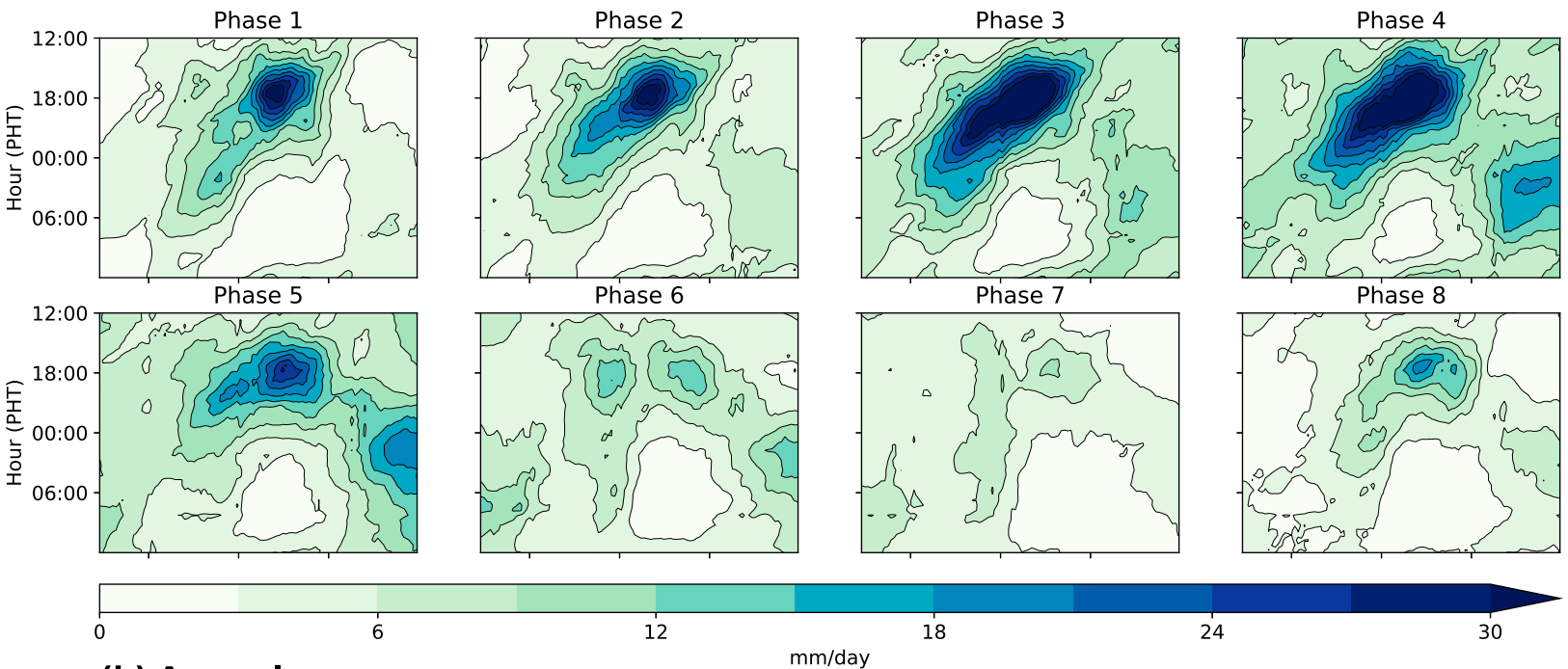

(b) Anomaly
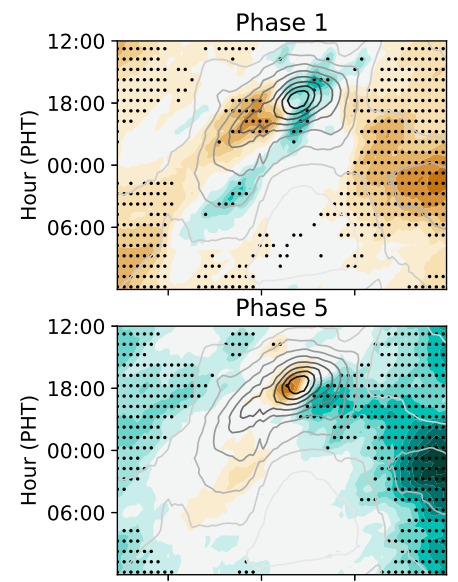

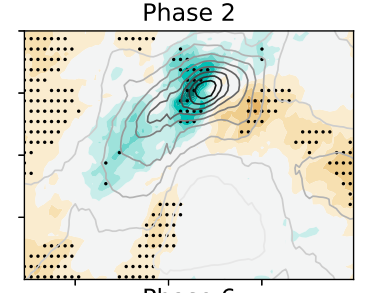

Phase 6

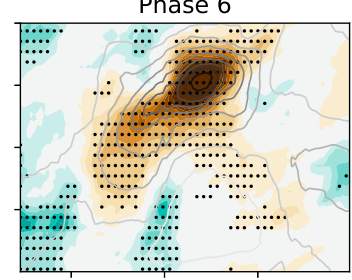

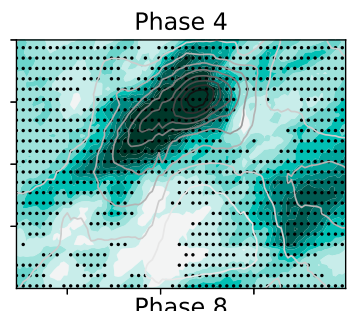
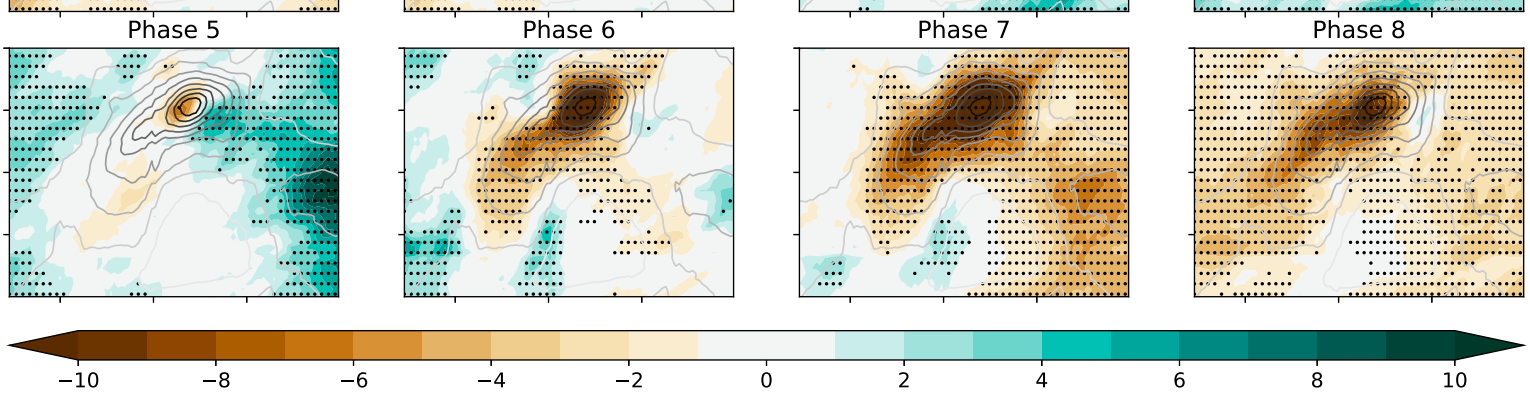

$-2$

$\mathrm{mm} / \mathrm{day}$
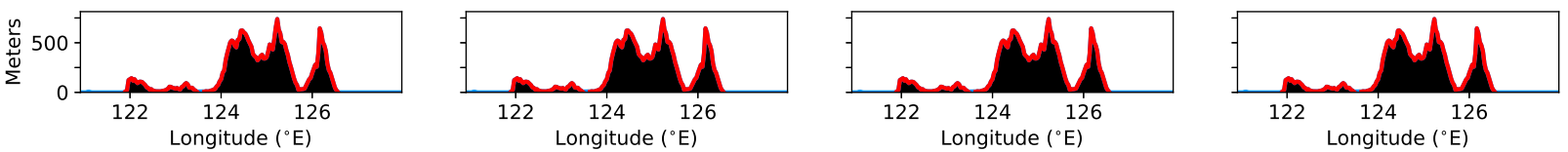

FIG. 9. As in Fig. 7, but for Mindanao (box B).

circulation and more vigorous convection. Surface insolation is strongly reduced by phase 6 , providing less forcing for a strong diurnal cycle.

The strength of the land-sea breeze circulation is estimated in Fig. 11b, which shows the BSISO anomalies of the diurnal amplitude of surface zonal wind. For coastlines oriented north to south, the zonal wind can be thought of as the onshore/offshore component of the wind. Positive anomalies of this quantity indicate a strengthened sea-breeze circulation, or, that the wind is more onshore during the afternoon hours and more offshore during the overnight hours. In phase 2, strong sea-breeze circulations are present over much of the coastal waters of the South China Sea, concurrent with the elevated insolation at this time. A heightened diurnal cycle in surface wind is still present on the west coast of Luzon in phase 4, but gives way to predominantly suppressed amplitude sea-breeze circulations in phase 6, when the main BSISO convective envelope is overhead. 

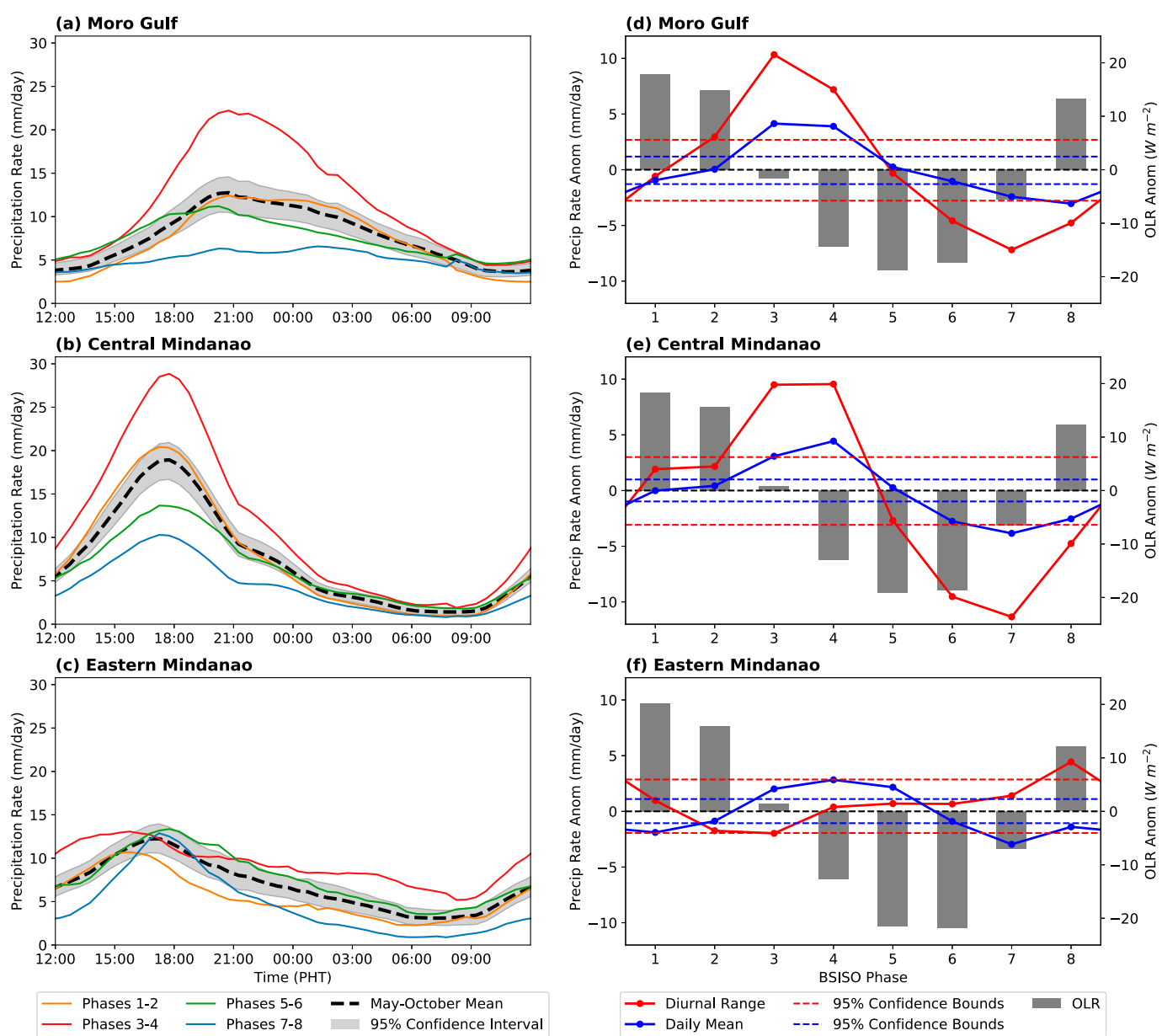

FIG. 10. As in Fig. 8, but for Mindanao [boxes F (ocean points only) and G and H (land points only)].

Taken together, these results support the hypothesis that increased insolation associated with the suppressed BSISO period leads to a stronger sea-breeze circulation, and thus a high-amplitude diurnal cycle in precipitation. However, this mechanism alone would suggest a diurnal cycle peak over Luzon in phase 2, the middle of the suppressed period, not in phase $3-4$ as is observed. Thus, other mechanisms must be acting as well, consistent with other studies that have noted that insolation alone is insufficient to explain the observed peak in the diurnal amplitude of precipitation during the transition period (Peatman et al. 2014; Birch et al. 2016).

\section{b. Moisture}

To provide a plausible explanation for why the diurnal cycle is stronger at the end of the suppressed period when compared to the beginning, as well as to address the preference for offshore propagation in the transition period, tropospheric moisture anomalies are considered. For the boreal winter MJO, Peatman et al. (2014) argued that frictional moisture convergence associated with the pressure trough extending to the east of MJO convection along the equator could explain why the diurnal cycle is elevated before large-scale convective onset, but not after. However, analysis of boundary layer moisture convergence in ERA5 (not shown) suggests that it does not systematically lead large-scale BSISO convection, and the off-equatorial locations examined here do not suggest a significant role for Kelvin wave dynamics.

Other studies (e.g., Hassim et al. 2016; Vincent and Lane 2016, 2017) have pointed to ambient free-tropospheric moisture as a critical factor in driving the active diurnal cycle prior to ISO convection. A close relationship between free-tropospheric water vapor and tropical convection has been well established (Bretherton et al. 2004). In particular, there is evidence that lower-to-middle-freetropospheric moisture is associated with enhanced deep convection by suppressing entrainment drying (Holloway and Neelin 2009, 2010; Yuan and Houze 2013).

Figure 12a shows the BSISO composite anomalies of total column water vapor from ERA5. While statistical 


\section{(a) Surface Downwelling Shortwave}

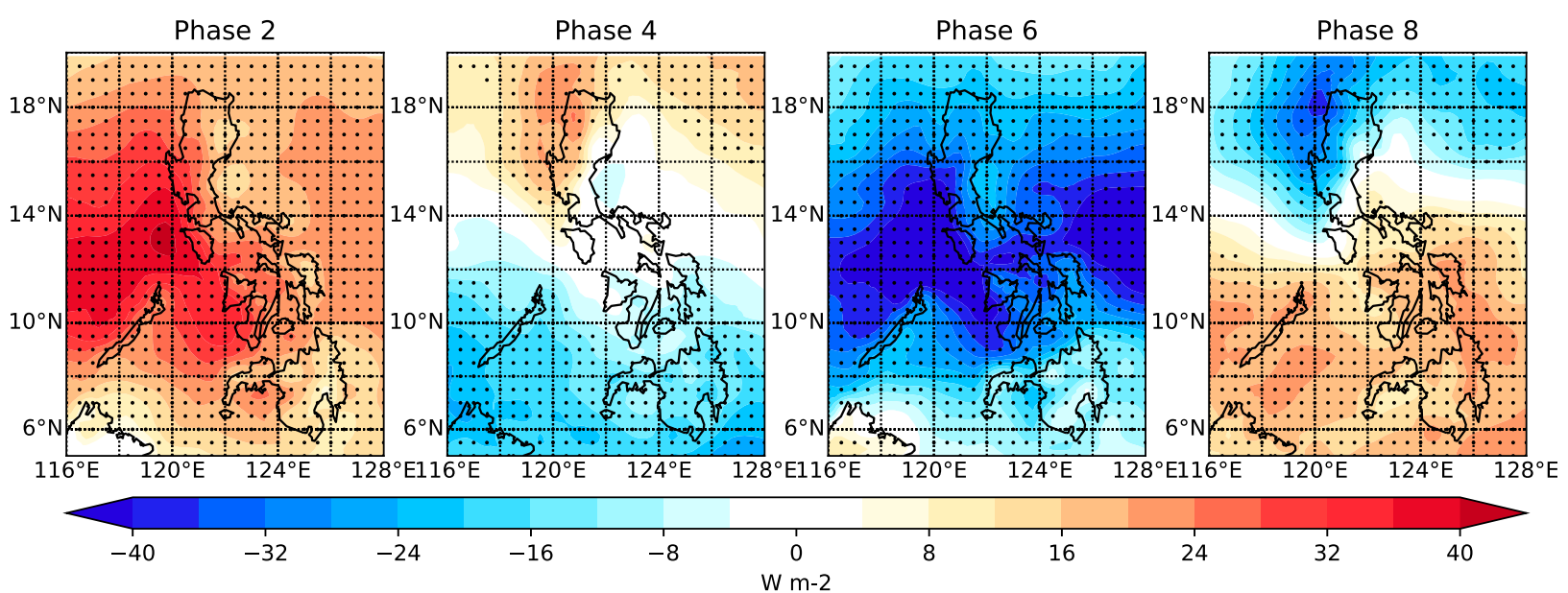

(b) Diurnal Amplitude of 10-m Zonal Wind

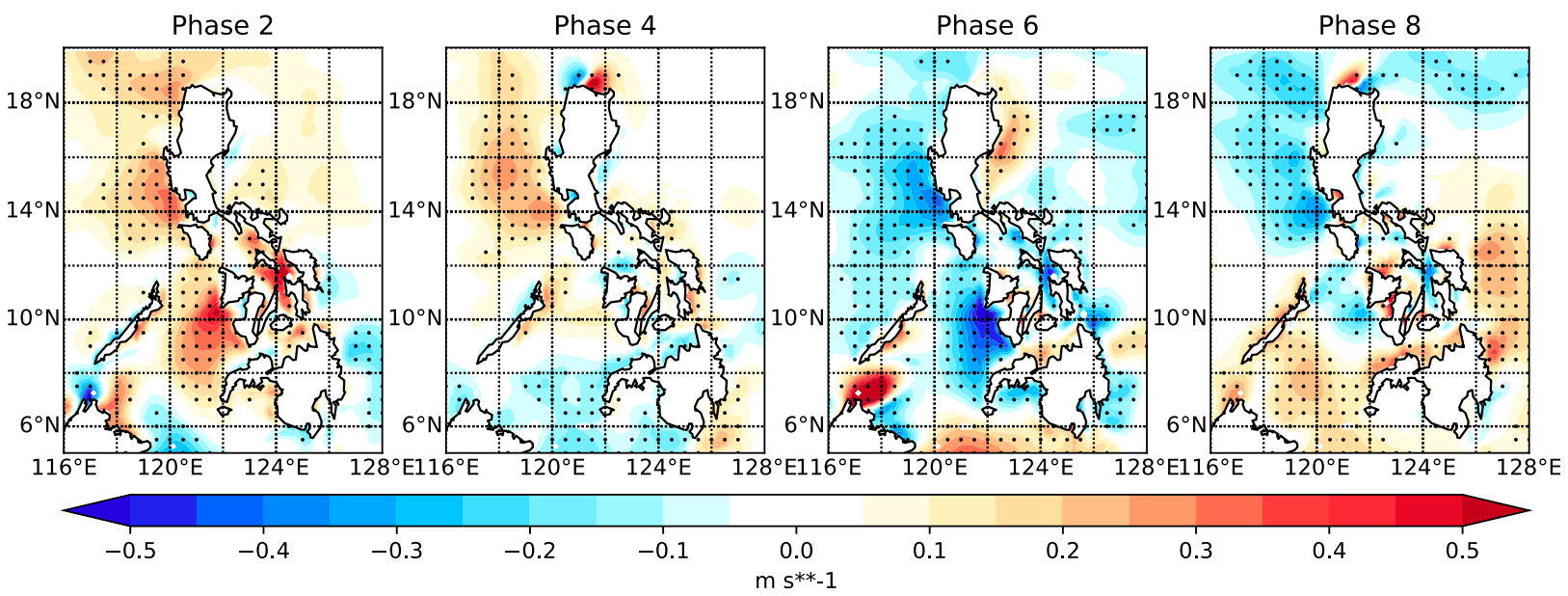

FIG. 11. ERA5 (a) daily mean surface downwelling shortwave radiation anomalies by BSISO phase relative to the May-October mean and (b) BSISO anomalies of the diurnal amplitude of surface zonal wind relative to May-October composite diurnal cycle of zonal wind. Statistical significance calculated with a bootstrap method is shown as black dots.

significance is not shown in this figure, anomalies exceeding the minimum contour line chosen are generally significant, with the exception of the area around Luzon in phase 4 . When compared with Fig. 4, this figure indicates that total column water vapor tracks the enhanced convective envelope of the BSISO. Strong dry anomalies are present over the northern Philippines in phase 2, the middle of the suppressed period, which gradually transition to strong moist anomalies by phase 6 . While insolation is sufficient to initiate diurnal convection over land during the suppressed period, the anomalously dry troposphere may suppress offshore propagation through entrainment drying. High insolation is still present during phase 4 (Fig. 11a), but dry anomalies have substantially weakened (Fig. 12). Near-zero moisture anomalies reduce the robust entrainment drying that is likely in phase 2 . As a result, convection may be able to propagate farther offshore during the overnight hours, consistent with theory of tropical convection (Bretherton et al. 2004; Holloway and Neelin 2009, 2010) and the hypothesis for the diurnal cycle discussed in past studies for New Guinea and Sumatra (Hassim et al. 2016; Vincent and Lane 2016, 2018).

The moistening of the lower free troposphere through horizontal advection ahead of the BSISO convective envelope (Jiang et al. 2018; Johnson and Ciesielski 2013; Maloney 2009; Sobel et al. 2014) may contribute to the longevity of diurnally generated thunderstorms in the transition phase. This mechanism combined with relatively high insolation provides a plausible explanation for the preference of robust offshore propagation to 
(a) Total Column Water Vapor Anomaly and Mean Surface Wind Vectors

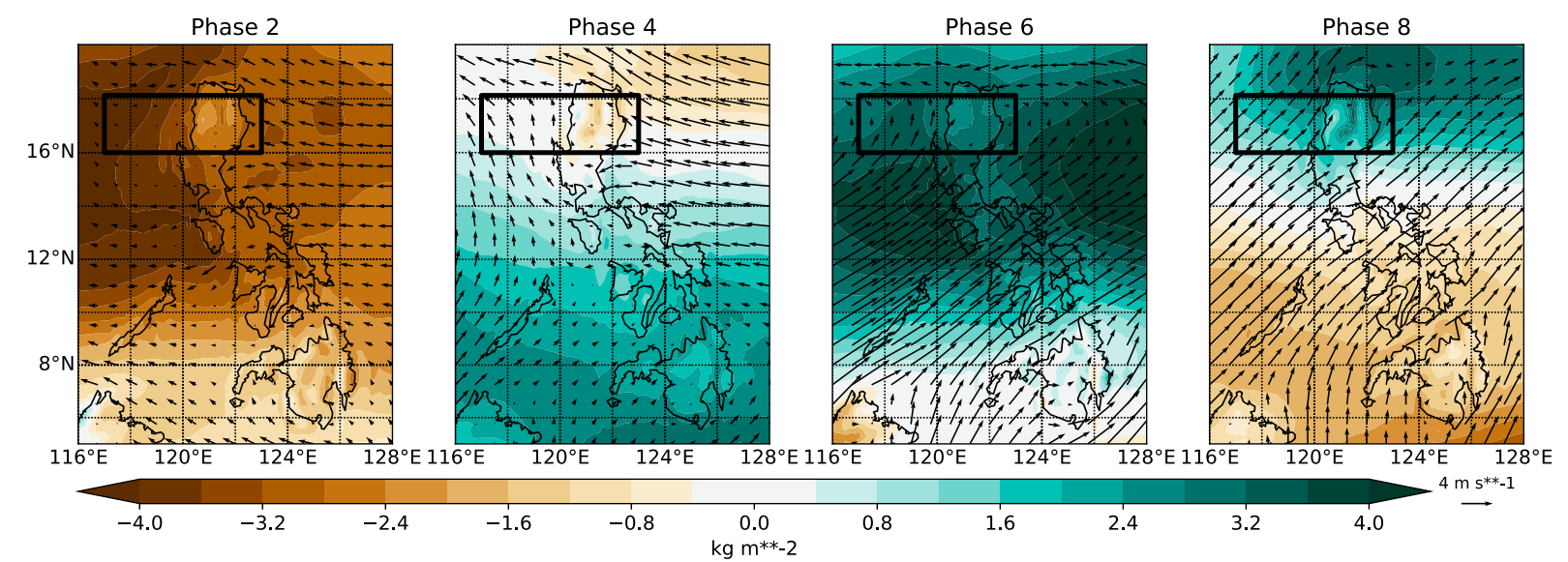

(b) Specific Humidity Anomaly and Mean uw-Wind Vectors
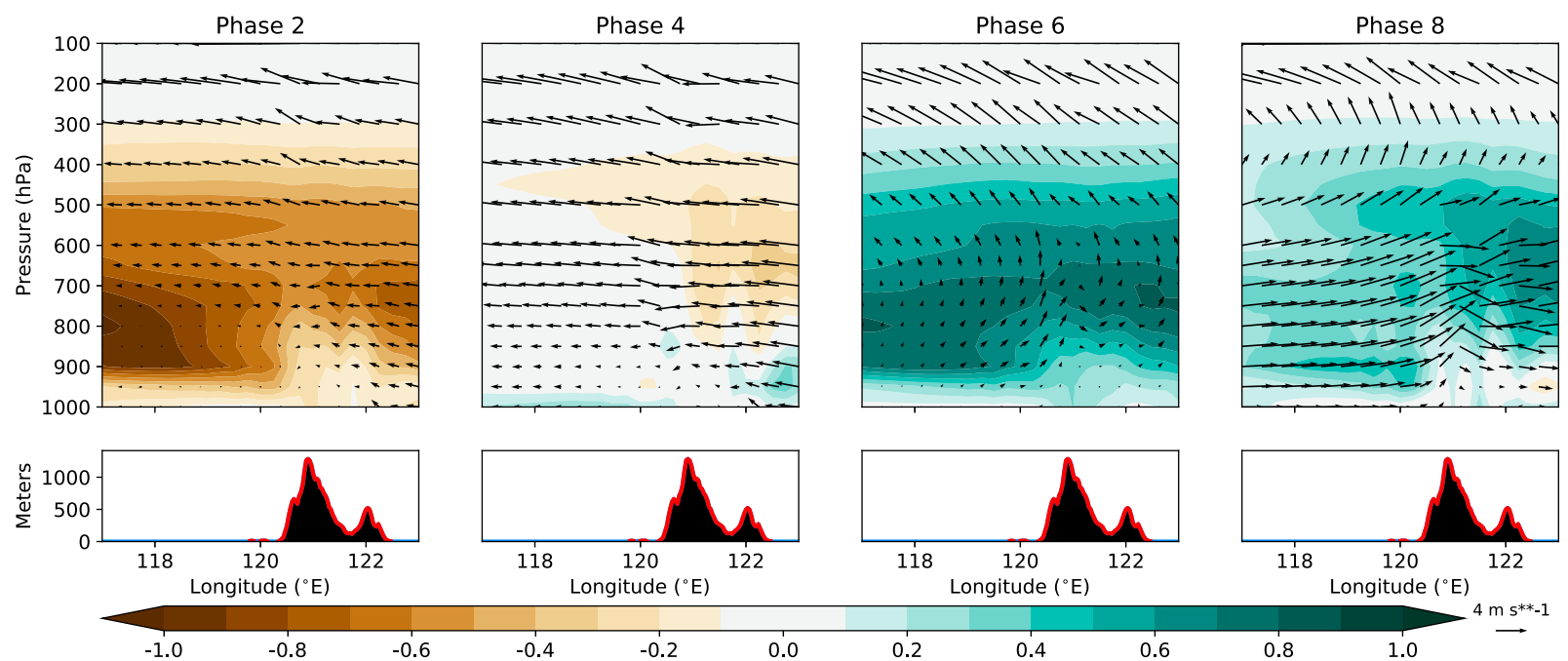

$\begin{array}{llllll}-1.0 & -0.8 & -0.6 & -0.4 & -0.2 & \begin{array}{c}0.0 \\ \mathrm{~g} \mathrm{~kg}^{* *}-1\end{array}\end{array}$

FIG. 12. (a) ERA5 BSISO anomalies of total column water vapor with BSISO composite (not anomaly) surface wind vectors, and (b) ERA5 BSISO anomalies of latitudinally averaged specific humidity [inside the black-outlined box in (a)] by longitude and height (in pressure coordinates), with BSISO composite (not anomaly) zonal-vertical wind vectors averaged over the same latitudes, with average topography shown below. The vertical component of the wind has been multiplied by 100 .

occur during the transition from suppressed to active BSISO state. Another mechanism that could further enhance the diurnal cycle over land at the end of the suppressed period will be explored next.

\section{c. Prevailing wind}

Many prior studies (e.g., Saito et al. 2001; Ichikawa and Yasunari 2006, 2008; Fujita et al. 2011; Oh et al. 2012; Wang and Sobel 2017; Yanase et al. 2017) have shown that the background wind profile can have an impact on the diurnal cycle of convection. This will be explored in the context of the BSISO. Figure 12 also shows composite wind vectors by BSISO phase. Figure 12a shows the horizontal winds at the surface, while Fig. $12 \mathrm{~b}$ shows the $u$ - and $w$-component winds averaged latitudinally over the black box shown over Luzon in Fig. 12a. Of prime interest is the fact that while total column water vapor and surface insolation display similar values over Luzon in phases 4 and 8, the wind fields are dramatically different.

In BSISO phase 4, the monsoon trough (as seen by converging surface wind vectors in Fig. 12a) is oriented from northwest to southeast across the center of the Philippines. As a result the winds over Luzon are still predominantly in the trade easterly regime throughout the troposphere (Fig. 12b). Strong onshore flow is present on the eastern side of the island, with weak offshore flow on the western side. In phase 8, the monsoon trough is positioned to the northeast of the archipelago and strong southwesterly monsoon flow is 
present across the Philippines. This manifests as strong onshore flow on the western slope of Luzon's topography, and strong offshore flow to the east. Westerly flow reaches as deep as $400 \mathrm{hPa}$ before returning to easterly near the tropopause.

It is argued here consistent with prior work (Fujita et al. 2011; Oh et al. 2012; Wang and Sobel 2017) that the low-level flow plays an important role in modulating the diurnal cycle of convection over the islands of the MC. Strong onshore flow impinging upon the western Philippine Islands may help weaken the diurnal cycle during the late-active and transition back to suppressed period. These winds are daily averages (Fig. 12), and are consistently onshore through the day in phases $6-8$, helping to ventilate the land surface and reduce the land-sea contrast and sea-breeze circulation. Furthermore, prevailing onshore winds may reduce convergence between the diurnal sea breeze and the background flow, similar to ideas discussed by Houze et al. (1981) and Oh et al. (2012).

The same mechanism could work in the opposite sense to promote a strong diurnal cycle at the tail end of the suppressed BSISO phase. When the prevailing BSISO winds are easterly, as in phases $2-4$, convergence over the western shore between the sea-breeze and background flow is enhanced, and the weaker offshore flow is less effective at ventilating the land surface (Saito et al. 2001; Fujita et al. 2011; Oh et al. 2012). The result is an active diurnal cycle on the leeward side of the Philippines, as is observed (Fig. 8e). This is also in agreement with previous studies that have shown that extreme heavy rainfall events can occur on the western side or just offshore of MC islands with the onset of the westerly wind burst (Park et al. 2011; Wu et al. 2017).

Another hypothesis comes from the interaction of this prevailing wind with the topography of the Philippine Islands. An onshore and upslope fetch from the ocean could result in increased cloudiness on the windward side of the islands, thus further reducing surface insolation. However, there would be conflicting impacts on the leeward side between downslope flow driving greater surface insolation favoring convection, but also its drying influence inhibiting convection. More work is required to see if this mechanism is plausible. Insolation changes possibly associated with prevailing wind may also be reflected in Fig. 11a, which shows generally higher insolation on the leeward side of the islands in all BSISO phases when compared to the windward side, although it is unclear whether ERA5 captures these finescale topographic features.

The disparity between the eastern and western portions of the islands can also be explained with this proposed mechanism. When the trades dominate as in phases 2-4, the eastern shore of the Philippine Islands experiences onshore, upslope flow, concurrent with the smallest-amplitude diurnal cycles observed for this region. The eastern sides of the major Philippine Islands see the strongest diurnal cycles in the transition period from active back to suppressed (opposite the western side), which is coincident with offshore background flow.

Consideration of the zonal wind shear shown qualitatively in Fig. 12b present some interesting ideas in the context of work by Tulich and Kiladis (2012). Examination of the wind vectors between roughly 900 and $600 \mathrm{hPa}$ reveals weak easterly shear over Luzon in phases 2 and 6 , strong easterly shear in phase 4 , and westerly shear in phase 8 . Tulich and Kiladis (2012) proposed that easterly shear in the lower levels is essential in producing the preferred westward propagation of convection in the tropics. These results are consistent with that hypothesis, as phase 4 and 5 experience the strongest easterly shear in association with the most robust westward propagation (Fig. 7). Furthermore, when the shear is most westerly in phase 8 during the transition back to suppressed conditions, there is some evidence of enhanced eastward propagation of the diurnal cycle.

\section{Summary and conclusions}

This study has used the Philippine archipelago as a case study to address ongoing questions about the impact of the tropical intraseasonal oscillation on the diurnal cycle of precipitation in the MC. A further motivation is the recent interest in this topic associated with the Propagation of Intraseasonal Tropical Oscillations field campaign (PISTON; https://onrpiston.colostate.edu/). Prior work has been done exploring this issue (Birch et al. 2016; Peatman et al. 2014; Sakaeda et al. 2017, among others), although the vast majority has focused on the boreal winter season near the equator. Others have examined some aspects of intraseasonal variability in the diurnal cycle near the Philippines to show a preference for strong convection over land during the suppressed period (Chen and Takahashi 1995; Ho et al. 2008; Park et al. 2011; Xu and Rutledge 2018), but a comprehensive understanding of the evolution of the diurnal cycle during the BSISO life cycle and the mechanisms driving this variability remains incomplete. This study applies ideas proposed for the impact of the wintertime MJO on the MC diurnal cycle (Ichikawa and Yasunari 2006, 2008; Oh et al. 2012; Peatman et al. 2014; Vincent and Lane 2017; Wu et al. 2018) to the boreal summer season off the equator. The main findings of this study are summarized here: 
- In May-October, the diurnal cycle of precipitation over the Philippines generally peaks over land during the late afternoon to early evening, and then propagates westward into the South China Sea (Figs. 2 and 3).

- A statistically significant enhancement of diurnal cycle amplitude is observed at the end of the suppressed phase of the BSISO (phase 3) over and west of high topography. The diurnal amplitude is minimized at the end of the convectively active period (phase 7; Figs. 8b,e and 10b,e).

- Offshore propagation of diurnally generated convection into the South China Sea is maximized in the transition phase from suppressed to active large-scale BSISO conditions (phase 4) and minimized in the reverse transition (phase 7-8; Figs. 7, 9, 8d and 10d).

- Daily mean precipitation is in phase with the diurnal amplitude over Mindanao but is nearly out of phase over Luzon (Figs. 5, 6, 8 and 10).

- There is a marked disparity in diurnal cycle behavior between eastern and western sides of the high topography of the Philippines (Figs. 8b,c and 10b,c), possibly related to prevailing wind direction (Fig. 12)

- The preference for a strong diurnal cycle before BSISO convective onset is hypothesized to be due to the interplay between strong insolation in the suppressed phase increasing the land-sea contrast (Fig. 11), the increase in free-tropospheric moisture prior to the arrival of large-scale convection, and the prevailing wind direction (Fig. 12).

Major findings of this study will now be discussed in detail. A high-resolution boreal summer composite of satellite derived (CMORPH) precipitation for the Philippines shows similar behavior in this region to other regions of the MC explored in prior studies (e.g., Dai 2001; Yang and Slingo 2001; Mori et al. 2004; Qian 2008; Hassim et al. 2016). In particular, sea-breeze and mountain-valley circulations initiate convection over land during the afternoon, leading to a precipitation peak in the late afternoon to early evening hours (Houze et al. 1981; Saito et al. 2001; Mori et al. 2004; Qian 2008; Sato et al. 2009; Birch et al. 2015). Precipitation systems propagate offshore overnight, predominantly to the west, likely related to gravity waves initiated by convective or stratiform heating over land (Mapes et al. 2003a; Love et al. 2011; Hassim et al. 2016; Yokoi et al. 2017; Vincent and Lane 2018).

The diurnal cycle exhibits substantial variability on intraseasonal time scales. This study examined eight composite diurnal cycles for each phase of the boreal summer intraseasonal oscillation according to an index by Lee et al. (2013). Statistically significant differences in daily mean precipitation and the amplitude of the composite diurnal cycles as a function of BSISO phase were found over land and coastal waters, indicating a large-scale influence on the formation and propagation of diurnal convective systems. One intriguing finding is that the diurnal cycle amplitude is in phase with daily mean precipitation over Mindanao, but nearly out of phase over Luzon.

In the early suppressed period (BSISO phases 1 and 2), precipitation is strongly suppressed over ocean at all times of day. Precipitation rates over land are reduced at all times of day except during and just before the usual late afternoon peak in the diurnal cycle, consistent with prior work (Chen and Takahashi 1995; Ho et al. 2008; Peatman et al. 2014; Katsumata et al. 2018; Xu and Rutledge 2018). Cloud cover is strongly reduced during this period, leading to positive surface insolation anomalies and a strong thermally driven sea-breeze circulation that maintains a potent diurnal cycle. Diurnally generated convective activity is short-lived, showing weak propagation offshore. This may be caused by a very dry nearshore troposphere that suppresses precipitation through entrainment drying.

During the transition to the active phase (phases 3-5), insolation is still near average as the large-scale cloudiness associated with the BSISO approaches from the southwest. These phases also correspond to the strongest easterly trade winds over the Philippine Islands. Furthermore, moisture in the free troposphere begins to gradually increase. The Philippines (primarily on the western side of the islands) see their strongest diurnal cycles at this time in agreement with prior studies that have showed a preference for strong diurnal cycles and heavy precipitation in the ISO transition period (Park et al. 2011; Peatman et al. 2014; Sakaeda et al. 2017; Wu et al. 2017). Convection persists later into the night, propagating farther offshore. Longer storm lifetimes are possibly associated with greater moisture availability and reduced dry air entrainment.

While under the main BSISO convective envelope and its transition back to suppressed conditions (phases 6-8), precipitation is elevated over the ocean throughout the day. Over Luzon, precipitation rates tend to be anomalously high at all times of day except during the typical afternoon peak. Thus, the diurnal cycle amplitude is reduced, supporting findings from studies focusing on other islands in the MC (Peatman et al. 2014; Birch et al. 2016; Vincent and Lane 2016, 2017; Wu et al. 2017; Yokoi et al. 2017). The diurnal cycle in precipitation also peaks slightly later than in the boreal summer mean, possibly related to lingering stratiform precipitation (Sakaeda et al. 2017). Mindanao does not see the increase in precipitation during off peak times, so both the diurnal cycle and daily mean precipitation rates are 
both strongly suppressed. Reduced insolation due to increased cloudiness over land is present in this phase along with strong onshore monsoonal flow out of the west or southwest that ventilates the land surface. Together, these mechanisms can act to reduce the thermal contrast and thus the sea-breeze circulation and the diurnal cycle amplitude over land.

Eastern portions of the Philippines exhibit markedly different behavior through the BSISO life cycle. During the transition from suppressed to active BSISO, this region is subject to moderate onshore wind flow in the lower levels. This could lead to reduced convergence on land and increased cloudiness due to upslope flow, inhibiting the strength of the diurnal cycle. This supports arguments discussed in several past studies (Saito et al. 2001; Fujita et al. 2011; Oh et al. 2012; Wang and Sobel 2017). The transition from active to suppressed for the eastern shore is somewhat analogous to the suppressed to active transition on the western shore, that is, when prevailing offshore flow is at its peak, combined with near-average insolation and free-tropospheric moisture anomalies. Furthermore, there is some evidence of increased offshore propagation to the east into the Philippine sea during this transition (phases 8 and 1).

This study has showed that there is a plausible connection between several mechanisms (prevailing low-level winds, insolation, and free-tropospheric moisture) and the diurnal cycle amplitude through the BSISO life cycle, but causation was not established. These mechanisms warrant future modeling studies to determine a possible cause and effect relationship. An interesting disparity in diurnal cycle behavior between eastern and western sides of Luzon and Mindanao has also been shown, which invites a more detailed analysis of other MC islands that might reveal a similar contrast. Variability on the subisland scale suggests the importance of local topographic factors in driving the precipitation response to the BSISO.

It has also been shown that the diurnal cycle amplitude and daily mean precipitation rate over large MC islands can be out of phase, as is the case for Luzon. Further research could explore the relationship between the two in detail in order to determine why some islands have higher precipitation variability at night than others (Figs. 8 and 10). Finally, the potential relationship between free-tropospheric moisture and the propagating diurnal cycle motivates speculation of a possible upscale feedback from the diurnal cycle back to the BSISO in light of recent work by Zhang and Ling (2017), who showed that MJO events that have relatively more precipitation over ocean compared to land are more likely to successfully propagate through the MC. It is possible that increased offshore propagation of the diurnal cycle in the BSISO transition phase supports northward propagation.

Acknowledgments. We thank three anonymous reviewers for their constructive comments that led to improvements in the original paper. This work was supported by the Office of Naval Research (ONR) under the Propagation of Tropical Intraseasonal Oscillations (PISTON) Project N00014-16-1-3087, the NOAA CVP program under Grant NA18OAR4310299, NASA CYGNSS Grant NNX17AH77G, and the Climate and Large Scale Dynamics Program of the National Science Foundation under Grant AGS-1735978.

\section{REFERENCES}

Annamalai, H., and J. M. Slingo, 2001: Active/break cycles: Diagnosis of the intraseasonal variability of the Asian summer monsoon. Climate Dyn., 18, 85-102, https://doi.org/10.1007/ s003820100161.

- and K. R. Sperber, 2005: Regional heat sources and the active and break phases of boreal summer intraseasonal (30-50 day) variability. J. Atmos. Sci., 62, 2726-2748, https://doi.org/10.1175/ JAS3504.1.

Bergemann, M., C. Jakob, and T. P. Lane, 2015: Global detection and analysis of coastline-associated rainfall using an objective pattern recognition technique. J. Climate, 28, 7225-7236, https:// doi.org/10.1175/JCLI-D-15-0098.1.

Biasutti, M., S. E. Yuter, C. D. Burleyson, and A. H. Sobel, 2012: Very high resolution rainfall patterns measured by TRMM Precipitation Radar: Seasonal and diurnal cycles. Climate Dyn., 39, 239-258, https://doi.org/10.1007/s00382-0111146-6.

Birch, C. E., M. J. Roberts, L. Garcia-Carreras, D. Ackerley, M. J. Reeder, A. P. Lock, and R. Schiemann, 2015: Seabreeze dynamics and convective initiation: The influence of convective parameterization in weather and climate model biases. J. Climate, 28, 8093-8108, https://doi.org/10.1175/ JCLI-D-14-00850.1.

— S. Webster, S. C. Peatman, D. J. Parker, A. J. Matthews, Y. Li, and M. E. E. Hassim, 2016: Scale interactions between the MJO and the western Maritime Continent. J. Climate, 29, 2471-2492, https://doi.org/10.1175/JCLI-D-15-0557.1.

Bretherton, C. S., M. E. Peters, and L. E. Back, 2004: Relationships between water vapor path and precipitation over the tropical oceans. J. Climate, 17, 1517-1528, https://doi.org/ 10.1175/1520-0442(2004)017<1517:RBWVPA>2.0.CO;2.

C3S, 2017: ERA5: Fifth generation of ECMWF atmospheric reanalyses of the global climate. Copernicus Climate Change Service Climate Data Store, accessed 15 July 2019, https:// cds.climate.copernicus.eu/cdsapp\#!/home.

Chen, T.-C., and K. Takahashi, 1995: Diurnal variation of outgoing longwave radiation in the vicinity of the South China Sea: Effect of intraseasonal oscillation. Mon. Wea. Rev., 123, 566-577, https://doi.org/10.1175/1520-0493(1995) $123<0566$ :DVOOLR $>2.0$. CO; 2 .

Cronin, T. W., K. A. Emmanuel, and P. Molnar, 2015: Island precipitation enhancement and the diurnal cycle in 
radiative-convective equilibrium. Quart. J. Roy. Meteor. Soc., 141, 1017-1034, https://doi.org/10.1002/qj.2443.

Dai, A., 2001: Global precipitation and thunderstorm frequencies. Part II: Diurnal variations. J. Climate, 14, 1112-1128, https:// doi.org/10.1175/1520-0442(2001)014<1112:GPATFP>2.0.CO;2.

Dee, D. P., and Coauthors, 2011: The ERA-Interim reanalysis: Configuration and performance of the data assimilation system. Quart. J. Roy. Meteor. Soc., 137, 553-597, https://doi.org/ 10.1002/qj.828.

Fujita, M. K., K. Yoneyama, S. Mori, T. Nasuno, and M. Satoh, 2011: Diurnal convection peaks over the eastern Indian Ocean off Sumatra during different MJO phases. J. Meteor. Soc. Japan, 89A, 317-330, https://doi.org/10.2151/jmsj.2011-A22.

Gill, A. E., 1980: Some simple solutions for heat-induced tropical circulation. Quart. J. Roy. Meteor. Soc., 106, 447-462, https:// doi.org/10.1002/qj.49710644905.

Gray, W. M., and R. W. Jacobson, 1977: Diurnal variation of deep cumulus convection. Mon. Wea. Rev., 105, 1171-1188, https:// doi.org/10.1175/1520-0493(1977)105<1171:DVODCC > 2.0.CO;2.

Hagos, S. M., C. Zhang, Z. Feng, C. D. Burleyson, C. DeMott, B. Kerns, J. J. Benedict, and M. N. Martini, 2016: The impact of the diurnal cycle on the propagation of Madden-Julian oscillation convection across the Maritime Continent. $J$. $A d v$. Model. Earth Syst., 8, 1552-1564, https://doi.org/10.1002/ 2016MS000725.

Hassim, M. E. E., T. P. Lane, and W. W. Grabowski, 2016: The diurnal cycle of rainfall over New Guinea in convection-permitting WRF simulations. Atmos. Chem. Phys., 16, 161-175, https:// doi.org/10.5194/acp-16-161-2016.

Hendon, H. H., and B. Liebmann, 1994: Organization of convection within the Madden-Julian oscillation. J. Geophys. Res., 99, 8073-8083, https://doi.org/10.1029/94JD00045.

_ , and M. L. Salby, 1994: The life cycle of the Madden-Julian oscillation. J. Atmos. Sci., 51, 2225-2237, https://doi.org/10.1175/ 1520-0469(1994)051<2225:TLCOTM>2.0.CO;2.

Ho, C.-H., M.-S. Park, Y.-S. Choi, and Y. N. Takayabu, 2008: Relationship between intraseasonal oscillation and diurnal variation of summer rainfall over the South China Sea. Geophys. Res. Lett., 35, L03701, https://doi.org/10.1029/ 2007GL031962.

Holloway, C. E., and J. D. Neelin, 2009: Moisture vertical structure, column water vapor, and tropical deep convection. J. Atmos. Sci., 66, 1665-1683, https://doi.org/10.1175/2008JAS2806.1.

- , and -2010 : Temporal relations of column water vapor and tropical precipitation. J. Atmos. Sci., 67, 1091-1105, https:// doi.org/10.1175/2009JAS3284.1.

Houze, R. A., Jr., S. G. Geotis, F. D. Marks Jr., and A. K. West, 1981: Winter monsoon convection in the vicinity of north Borneo. Part I: Structure and time variation of the clouds and precipitation. Mon. Wea. Rev., 109, 1595-1614, https://doi.org/ 10.1175/1520-0493(1981)109<1595:WMCITV>2.0.CO;2.

Huffman, G. J., and Coauthors, 2007: The TRMM Multisatellite Precipitation Analysis (TMPA): Quasi-global, multiyear, combined-sensor precipitation estimates at fine scales. J. Hydrometeor., 8, 38-55, https://doi.org/10.1175/JHM560.1.

Ichikawa, H., and T. Yasunari, 2006: Time-space characteristics of diurnal rainfall over Borneo and surrounding oceans as observed by TRMM-PR. J. Climate, 19, 1238-1260, https://doi.org/ 10.1175/JCLI3714.1.

, and -2008 : Intraseasonal variability in diurnal rainfall over New Guinea and the surrounding oceans during austral summer. J. Climate, 21, 2852-2868, https://doi.org/10.1175/2007JCLI1784.1.
Iguchi, T., T. Kozu, R. Meneghini, J. Awaka, and K. Okamoto, 2000: Rain-profiling algorithm for the TRMM Precipitation Radar. J. Appl. Meteor., 39, 2038-2052, https://doi.org/10.1175/ 1520-0450(2001)040<2038:RPAFTT > 2.0.CO;2.

Inness, P. M., and J. M. Slingo, 2006: The interaction of the Madden-Julian oscillation with the Maritime Continent in a GCM. Quart. J. Roy. Meteor. Soc., 132, 1645-1667, https://doi.org/ 10.1256/qj.05.102.

Jiang, X., Á. F. Adames, M. Zhao, D. E. Waliser, and E. D. Maloney, 2018: A unified moisture mode framework for seasonality of the Madden-Julian oscillation. J. Climate, 31, 4215-4224, https:// doi.org/10.1175/JCLI-D-17-0671.1.

Johnson, R. H., and P. E. Ciesielski, 2013: Structure and properties of the Madden-Julian oscillations deduced from DYNAMO sounding arrays. J. Atmos. Sci., 70, 3157-3179, https://doi.org/ 10.1175/JAS-D-13-065.1.

— T. M. Rickenbach, S. A. Rutledge, P. E. Ciesielski, and W. H. Schubert, 1999: Trimodal characteristics of tropical convection. J. Climate, 12, 2397-2418, https://doi.org/10.1175/1520-0442(1999) 012<2397:TCOTC $>2.0 . \mathrm{CO} ; 2$.

Joyce, R. J., J. E. Janowiak, P. A. Arkin, and P. Xie, 2004: CMORPH: A method that produces global precipitation estimates from passive microwave and infrared data at high spatial and temporal resolution. J. Hydrometeor., 5, 487-503, https://doi.org/10.1175/1525-7541(2004)005<0487:CAMTPG > 2.0.CO;2.

Katsumata, M., S. Mori, J.-I. Hamada, M. Hattori, F. Syamsudin, and M. D. Yamanaka, 2018: Diurnal cycle over a coastal area of the Maritime Continent as derived by special networked soundings over Jakarta during HARIMAU2010. Prog. Earth Planet. Sci., 5, 64, https://doi.org/10.1186/s40645-018-0216-3.

Kawecki, S., and S. van den Heever, 2019: The roles of island size and orography on tropical convection and aerosol transport. Atmos. Chem. Phys. Discuss., https://doi.org/10.5194/ acp-2019-399.

Keenan, T. D., and R. E. Carbone, 2008: Propagation and diurnal evolution of warm season cloudiness in the Australian and Maritime Continent region. Mon. Wea. Rev., 136, 973-994, https://doi.org/10.1175/2007MWR2152.1.

Kemball-Cook, S. R., and B. Wang, 2001: Equatorial waves and air-sea interaction in the boreal summer intraseasonal oscillation. J. Climate, 14, 2923-2942, https://doi.org/10.1175/ 1520-0442(2001)014<2923:EWAASI > 2.0.CO;2.

Kikuchi, K., and B. Wang, 2008: Diurnal precipitation regimes in the global tropics. J. Climate, 21, 2680-2696, https://doi.org/ 10.1175/2007JCLI2051.1.

,-- , and Y. Kajikawa, 2012: Bimodal representation of the tropical intraseasonal oscillation. Climate Dyn., 38, 1989-2000, https://doi.org/10.1007/s00382-011-1159-1.

Kiladis, G. N., J. Dias, K. H. Straub, M. C. Wheeler, S. N. Tulich, K. Kikuchi, K. M. Weickmann, and M. J. Ventrice, 2014: A comparison of OLR and circulation-based indices for tracking the MJO. Mon. Wea. Rev., 142, 1697-1715, https://doi.org/ 10.1175/MWR-D-13-00301.1.

Knutson, T. R., and K. M. Weickmann, 1987: 30-60 day atmospheric oscillations: Composite life cycles of convection and circulation anomalies. Mon. Wea. Rev., 115, 1407-1436, https:// doi.org/10.1175/1520-0493(1987)115<1407:DAOCLC>2.0.CO;2.

Lau, K.-M., and P. H. Chan, 1986: Aspects of the 40-50 day oscillation during the northern summer as inferred from outgoing longwave radiation. Mon. Wea. Rev., 114, 1354-1367, https://doi.org/10.1175/1520-0493(1986)114<1354:AOTDOD> 2.0.CO;2. 
Lawrence, D. M., and P. J. Webster, 2002: The boreal summer intraseasonal oscillation: Relationship between northward and eastward movement of convection. J. Atmos. Sci., 59, 1593-1606, https://doi.org/10.1175/1520-0469(2002) 059<1593:TBSIOR $>2.0$. CO 2 .

Lee, J.-Y., B. Wang, M. C. Wheeler, X. Fu, D. E. Waliser, and I.-S. Kang, 2013: Real-time multivariate indices for the boreal summer intraseasonal oscillation over the Asian summer monsoon region. Climate Dyn., 40, 493-509, https://doi.org/ 10.1007/s00382-012-1544-4.

Liebmann, B., and C. A. Smith, 1996: Description of a complete (interpolated) outgoing longwave radiation dataset. Bull. Amer. Meteor. Soc., 77, 1275-1277, https://doi.org/10.1175/ 1520-0477-77.6.1274.

Love, B. S., A. J. Matthews, and G. M. S. Lister, 2011: The diurnal cycle of precipitation over the Maritime Continent in a high resolution atmospheric model. Quart. J. Roy. Meteor. Soc., 137, 934-947, https://doi.org/10.1002/qj.809.

Madden, R. A., and P. R. Julian, 1971: Detection of a 40-50 day oscillation in the zonal wind in the tropical Pacific. J. Atmos. Sci., 28, 702-708, https://doi.org/10.1175/1520-0469(1971) $028<0702$ :DOADOI $>2.0 . \mathrm{CO} ; 2$.

—_, and —-, 1972: Description of global-scale circulation cells in the tropics with a 40-50 day period. J. Atmos. Sci., 29, 1109-1123, https://doi.org/10.1175/1520-0469(1972) 029<1109:DOGSCC > 2.0.CO;2.

— , and 1994: Observations of the 40-50-day tropical oscillation-A review. Mon. Wea. Rev., 22, 813-837, https://doi.org/ 10.1175/1520-0493(1994)122<0814:OOTDTO > 2.0.CO;2.

Maloney, E. D., 2009: The moist static energy budget of a composite tropical intraseasonal oscillation in a climate model. J. Climate, 22, 711-729, https://doi.org/10.1175/2008JCLI2542.1.

Mapes, B. E., T. T. Warner, and M. Xu, 2003a: Diurnal patterns of rainfall in northwestern South America. Part III: Diurnal gravity waves and nocturnal convection offshore. Mon. Wea. Rev., 131，830-844, https://doi.org/10.1175/1520-0493(2003) $131<0830$ :DPORIN $>2.0$. CO; 2 .

,,,--- and A. J. Negri, 2003b: Diurnal patterns of rainfall in northwestern South America. Part I: Observations and context. Mon. Wea. Rev., 131, 799-812, https://doi.org/10.1175/ 1520-0493(2003)131<0799:DPORIN >2.0.CO;2.

Matthews, A. J., B. J. Hoskins, and M. Masutani, 2004: The global response to tropical heating in the Madden-Julian oscillation during the northern winter. Quart. J. Roy. Meteor. Soc., 130 1991-2011, https://doi.org/10.1256/qj.02.123.

Mori, S., J.-I. Hamada, Y. I. Tauhid, and M. D. Yamanaka, 2004: Diurnal land-sea rainfall peak migration over Sumatera island, Indonesian Maritime Continent, observed by TRMM satellite and intensive rawinsonde soundings. Mon. Wea. Rev., 132, 2021-2039, https://doi.org/10.1175/1520-0493(2004) 132<2021:DLRPMO > 2.0.CO;2.

Myers, D. S., and D. E. Waliser, 2003: Three-dimensional water vapor and cloud variations associated with the Madden-Julian oscillation during Northern Hemisphere winter. J. Climate, 16, 929-950, https://doi.org/10.1175/ 1520-0442(2003)016<0929:TDWVAC > 2.0.CO;2.

National Geophysical Data Center, 2006: 2-minute gridded global relief data (ETOPO2), version 2 . NOAA, accessed 12 February 2018, https://doi.org/10.7289/V5J1012Q.

Neale, R., and J. Slingo, 2003: The Maritime Continent and its role in the global climate: A GCM study. J. Climate, 16, 834-848, https://doi.org/10.1175/1520-0442(2003)016<0834:TMCAIR > 2.0.CO;2.
Ogino, S.-Y., M. D. Yamanaka, S. Mori, and J. Matsumoto, 2016: How much is the precipitation amount over the tropical coastal region? J. Climate, 29, 1231-1236, https://doi.org/ 10.1175/JCLI-D-15-0484.1.

Oh, J.-H., K.-Y. Kim, and G.-H. Lim, 2012: Impact of MJO on the diurnal cycle of rainfall over the western Maritime Continent in the austral summer. Climate Dyn., 38, 1167-1180, https:// doi.org/10.1007/s00382-011-1237-4.

Ohsawa, T., H. Ueda, T. Hayashi, A. Watanabe, and J. Matsumoto, 2001: Diurnal variations of convective activity and rainfall in tropical Asia. J. Meteor. Soc. Japan, 79B, 333-352, https:// doi.org/10.2151/jmsj.79.333.

Park, M.-S., C.-H. Ho, J. Kim, and R. L. Elsberry, 2011: Diurnal circulations and their multi-scale interaction leading to rainfall over the South China Sea upstream of the Philippines during intraseasonal monsoon westerly wind bursts. Climate Dyn., 37, 1483-1499, https://doi.org/10.1007/s00382-010-0922-z.

Peatman, S. C., A. J. Matthews, and D. P. Stevens, 2014: Propagation of the Madden-Julian oscillation through the Maritime Continent and scale interaction with the diurnal cycle of precipitation. Quart. J. Roy. Meteor. Soc., 140, 814-825, https:// doi.org/10.1002/qj.2161.

Qian, J., 2008: Why precipitation is mostly concentrated over islands in the Maritime Continent. J. Atmos. Sci., 65, 1428-1441, https://doi.org/10.1175/2007JAS2422.1

Ramage, C. S., 1968: Role of a tropical "Maritime Continent" in the atmospheric circulation. Mon. Wea. Rev., 96, 365-370, https://doi.org/10.1175/1520-0493(1968)096<0365:ROATMC $>$ 2.0.CO;2.

Rauniyar, S. P., and K. J. E. Walsh, 2011: Scale interaction of the diurnal cycle of rainfall over the Maritime Continent and Australia: Influence of the MJO. J. Climate, 24, 325-348, https://doi.org/10.1175/2010JCLI3673.1.

Riley, E. M., B. E. Mapes, and S. N. Tulich, 2011: Clouds associated with the Madden-Julian oscillation: A new perspective from CloudSat. J. Atmos. Sci., 68, 3032-3051, https://doi.org/10.1175/ JAS-D-11-030.1.

Robinson, F. J., S. C. Sherwood, D. Gerstle, C. Liu, and D. J. Kirshbaum, 2011: Exploring the land-ocean contrast in convective vigor using islands. J. Atmos. Sci., 68, 602-618, https:// doi.org/10.1175/2010JAS3558.1.

Saito, K., T. Keenan, G. Holland, and K. Puri, 2001: Numerical simulation of the diurnal evolution of tropical island convection over the Maritime Continent. Mon. Wea. Rev., 129, 378-400, https://doi.org/10.1175/1520-0493(2001)129<0378:NSOTDE > 2.0.CO;2.

Sakaeda, N., G. N. Kiladis, and J. Dias, 2017: The diurnal cycle of tropical cloudiness and rainfall associated with the MaddenJulian oscillation. J. Climate, 30, 3999-4020, https://doi.org/ 10.1175/JCLI-D-16-0788.1

Sakurai, N., and Coauthors, 2005: Diurnal cycle of cloud system migration over Sumatera Island. J. Meteor. Soc. Japan, 83, 835-850, https://doi.org/10.2151/jmsj.83.835.

Sato, T., H. Miura, M. Satoh, Y. N. Takayabu, and Y. Wang, 2009: Diurnal cycle of precipitation in the tropics simulated in a global cloud-resolving model. J. Climate, 22, 4809-4826, https://doi.org/ 10.1175/2009JCLI2890.1.

Sobel, A. H., C. D. Berleyson, and S. E. Yuter, 2011: Rain on small tropical islands. J. Geophys. Res., 116, D08102, https://doi.org/ 10.1029/2010JD014695

, S. Wang, and D. Kim, 2014: Moist static energy budget of the MJO during DYNAMO. J. Atmos. Sci., 71, 4276-4291, https:// doi.org/10.1175/JAS-D-14-0052.1. 
Sui, C.-H., and K.-M. Lau, 1992: Multiscale phenomena in the tropical atmosphere over the western Pacific. Mon. Wea. Rev., 120, 407-430, https://doi.org/10.1175/1520-0493(1992) $120<0407$ :MPITTA $>2.0 . \mathrm{CO} ; 2$.

Tabata, Y., H. Hashiguchi, M. K. Yamamoto, M. Yamamoto, M. D. Yamanaka, S. Mori, F. Syamsudin, and T. Manik, 2011: Observational study on diurnal precipitation cycle in equatorial Indonesia using 1.3-GHz wind profiling radar network and TRMM Precipitation Radar. J. Atmos. Sol.-Terr. Phys., 73, 1031-1042, https://doi.org/10.1016/j.jastp.2010.10.003.

Tan, J., W. A. Peterson, P.-E. Kirstetter, and Y. Tian, 2017: Performance of IMERG as a function of spatiotemporal scale. J. Hydrometeor., 18, 307-319, https://doi.org/10.1175/JHM-D16-0174.1.

Tulich, S. N., and G. N. Kiladis, 2012: Squall lines and convectively coupled gravity waves in the tropics: Why do most cloud systems propagate westward? J. Atmos. Sci., 69, 2995-3012, https:// doi.org/10.1175/JAS-D-11-0297.1.

Vincent, C. L., and T. P. Lane, 2016: Evolution of the diurnal precipitation cycle with the passage of a Madden-Julian oscillation event through the Maritime Continent. Mon. Wea. Rev., 144, 1983-2005, https://doi.org/10.1175/MWR-D-15-0326.1. , and —- 2017: A 10-year austral summer climatology of observed and modeled intraseasonal, mesoscale, and diurnal variations over the Maritime Continent. J. Climate, 30, 3807-3828, https://doi.org/10.1175/JCLI-D-16-0688.1.

$\ldots$, and — 2018: Mesoscale variation in diabatic heating around Sumatra, and its modulation with the Madden-Julian oscillation. Mon. Wea. Rev., 146, 2599-2614, https://doi.org/ 10.1175/MWR-D-17-0392.1.

— _ _ and M. C. Wheeler, 2016: A local index of Maritime Continent intraseasonal variability based on rain rates over the land and sea. Geophys. Res. Lett., 43, 9306-9314, https:// doi.org/10.1002/2016GL069987.

Wang, B., and X. Xu, 1997: Northern Hemisphere summer monsoon singularities and climatological intraseasonal oscillation. J. Climate, 10, 1071-1085, https://doi.org/10.1175/1520-0442(1997) $010<1071:$ NHSMSA $>2.0 . \mathrm{CO} ; 2$.

Wang, S., and A. H. Sobel, 2017: Factors controlling rain on small tropical islands: Diurnal cycle, large-scale wind speed, and topography. J. Atmos. Sci., 74, 3515-3532, https://doi.org/10.1175/ JAS-D-16-0344.1.

— , D. Ma, A. H. Sobel, and M. K. Tippett, 2018: Propagation characteristics of BSISO indices. Geophys. Res. Lett., 45, 9934-9943, https://doi.org/10.1029/2018GL078321.

Wheeler, M., and H. H. Hendon, 2004: An all-season real-time multivariate MJO index: Development of an index for monitoring and prediction. Mon. Wea. Rev., 132, 1917-1932, https://doi.org/ 10.1175/1520-0493(2004)132<1917:AARMMI>2.0.CO;2.

Wu, P., M. D. Yamanaka, and J. Matsumoto, 2008: The formation of nocturnal rainfall offshore from convection over western Kalimantan (Borneo) Island. J. Meteor. Soc. Japan, 86A, 187-203, https://doi.org/10.2151/jmsj.86A.187.
, M. Hara, J.-I. Hamada, M. D. Yamanaka, and F. Kimura, 2009: Why a large amount of rain falls over the vicinity of western Sumatra Island during nighttime. J. Appl. Meteor. Climatol., 48, 1345-1361, https://doi.org/10.1175/2009JAMC2052.1.

_, D. Ardiansyah, S. Yokoi, S. Mori, F. Syamsudin, and K. Yoneyama, 2017: Why torrential rain occurs on the western coast of Sumatra Island at the leading edge of the MJO westerly wind bursts. SOLA, 13, 36-40, https://doi.org/10.2151/ sola.2017-007.

__ S. Mori, and F. Syamsudin, 2018: Land-sea surface air temperature contrast on the western coast of Sumatra Island during an active phase of the Madden-Julian oscillation. Prog. Earth Planet. Sci., 5, 4, https://doi.org/10.1186/ s40645-017-0160-7.

Xie, P., R. Joyce, S. Wu, S.-H. Yoo, Y. Yarosh, F. Sun, and R. Lin, 2017: Reprocessed, bias-corrected CMORPH global highresolution precipitation estimates from 1998. J. Hydrometeor., 18, 1617-1641, https://doi.org/10.1175/JHM-D-16-0168.1.

Xu, W., and S. A. Rutledge, 2018: Convective variability associated with the boreal summer intraseasonal oscillation in the South China Sea region. J. Climate, 31, 7363-7383, https://doi.org/ 10.1175/JCLI-D-18-0091.1.

Yamamoto, M. K., F. A. Furuzawa, A. Higuchi, and K. Nakamura, 2008: Comparison of diurnal variations in precipitation systems observed by TRMM PR, TMI, and VIRS. J. Climate, 21, 4011-4028, https://doi.org/10.1175/2007JCLI2079.1.

Yamanaka, M. D., S.-Y. Ogino, P.-M. Wu, J.-I. Hamada, S. Mori, J. Matsumoto, and F. Syamsudin, 2018: Maritime Continent coastlines controlling Earth's climate. Prog. Earth Planet. Sci., 5, 21, https://doi.org/10.1186/s40645-018-0174-9.

Yanase, A., K. Yasunaga, and H. Masunaga, 2017: Relationship between the direction of diurnal rainfall migration and the ambient wind over the southern Sumatra Island. Earth Space Sci., 4, 117-127, https://doi.org/10.1002/2016EA000181.

Yang, G.-Y., and J. Slingo, 2001: The diurnal cycle in the tropics. Mon. Wea. Rev., 129, 784-801, https://doi.org/10.1175/1520-0493(2001) 129<0784:TDCITT $>2.0$. CO;2.

Yang, S., and E. A. Smith, 2006: Mechanisms for diurnal variability of global tropical rainfall observed from TRMM. J. Climate, 19, 5190-5226, https://doi.org/10.1175/JCLI3883.1.

Yokoi, S., S. Mori, M. Katsumata, B. Geng, K. Yasunaga, F. Syamsudin, Nurhayati, and K. Yoneyama, 2017: Diurnal cycle of precipitation observed in the western coastal area of Sumatra Island: Offshore preconditioning by gravity waves. Mon. Wea. Rev., 145, 3745-3761, https://doi.org/10.1175/ MWR-D-16-0468.1.

Yuan, J., and R. A. Houze Jr., 2013: Deep convective systems observed by A-Train in the tropical Indo-Pacific region affected by the MJO. J. Atmos. Sci., 70, 465-486, https://doi.org/ 10.1175/JAS-D-12-057.1.

Zhang, C., and J. Ling, 2017: Barrier effect of the Indo-Pacific Maritime Continent on the MJO: Perspectives from tracking MJO precipitation. J. Climate, 30, 3439-3459, https://doi.org/ 10.1175/JCLI-D-16-0614.1. 